\title{
Breve histórico do processo demográfico
}

\author{
Celso Cardoso Silva Simões
}

O presente capítulo tem como objetivo realizar uma síntese do processo de transição demográfica no Brasil, considerando as tendências, os padrões e os ritmos das principais variáveis demográficas, em especial a fecundidade e a mortalidade, tendo, como pano de fundo, o contexto socioeconômico e as diferenças regionais presentes no Território Nacional.

Procurou-se ainda, avaliar, ao longo desse processo, as alterações relacionadas com a esperança de vida ao nascer, a mortalidade infantil, a fecundidade e os impactos decorrentes sobre as estruturas etárias e suas consequências na redefinição das políticas públicas, levando em conta o peso de grupos populacionais específicos (crianças, jovens e idosos).

O capítulo está desmembrado em subitens, de forma a apresentar um panorama integrado do processo demográfico brasileiro, com ênfase a partir dos anos 1940, quando a produção de informações estatísticas e demográficas no País passa a ser mais consistente, incorporando, na medida do possível, as alterações observadas nos processos demográficos com os eventos considerados mais importantes na história do País.

Serão focados os seguintes aspectos relacionados com a dinâmica demográfica brasileira:

- Processo demográfico brasileiro; e

- Decomposição do crescimento demográfico brasileiro: a natalidade e a mortalidade; a esperança de vida ao nascer; a mortalidade infantil; as taxas de fecundidade total; e os impactos da queda da fecundidade sobre a estrutura etária e suas implicações sociais. 
Para que tal objetivo seja alcançado, serão utilizadas informações das Projeções da População do Brasil e das Unidades da Federação por Sexo e Idade, realizadas pelo IBGE (PROJEÇÃO..., 2013), até o ano 2050, obtidas pelo Método das Componentes Demográficas, levando em consideração hipóteses sobre o comportamento futuro das principais componentes da dinâmica demográfica: fecundidade, mortalidade e migrações ${ }^{1}$.

\section{Aspectos demográficos}

\section{Evolução da população brasileira e suas componentes demográficas}

A população do Brasil atingiu, em 1ํ de agosto de 2010, 190732694 habitantes. A taxa média geométrica de crescimento anual, no período de 2000-2010, foi de apenas $1,17 \%$, a mais baixa já observada, refletindo a continuidade do declínio da fecundidade, que se vem verificando no decorrer dos últimos 40 anos. Este declínio é generalizado no País, isto é, ocorre em todas as regiões, exprimindo-se na queda relativa e, em diversos casos, na redução até absoluta do número de nascimentos.

A maior aceleração no aumento da população brasileira ocorreu durante a década de 1950. Naquele período, a população cresceu a uma média de 3,0\% ao ano, correspondendo a um acréscimo relativo de $34,9 \%$ no efetivo populacional. Nessa época, enquanto a mortalidade acentuava seu processo de declínio, a fecundidade mantinha-se em patamares extremamente elevados. Posteriormente, inicia-se a desaceleração do crescimento em função de uma queda inicialmente tímida da fecundidade, o que fez com que a taxa de crescimento fosse inferior a 2,5\% ao ano na década de 1970. Entretanto, nas décadas seguintes, em consonância com a transição para níveis de fecundidade mais baixos, intensifica-se o declínio na taxa de crescimento, chegando-se aos patamares atuais, com taxas de crescimento, em torno de 1,2\% (Tabela 1 e Gráfico 1 ).

Outro aspecto importante da evolução da população brasileira está relacionado com o processo de urbanização. Até 1960, a maioria da população residia na área rural do País, à exceção da Região Sudeste que, nessa data, já apresentava $57,0 \%$ de sua população residente na área urbana. O fenômeno da urbanização no Brasil está estreitamente associado à questão das migrações internas que se intensificam a partir do início dos anos 1960 e tendo, inicialmente, como principal área de atração a Região Sudeste, que concentrava as maiores oportunidades de emprego, em decorrência da concentração das principais atividades econômicas então existentes no País. Já em 1970, a taxa de urbanização, nessa região, chega a $73,0 \%$, enquanto, nas demais, esse valor ainda é inferior a 50,0\%.

1 Nas Projeções realizadas para o Brasil, deixou de ser contemplada a variável migração. 
Tabela 1 - População nas datas dos recenseamentos gerais, taxas médias de crescimento anual e variação da taxa de crescimento - Brasil - 1872/2010

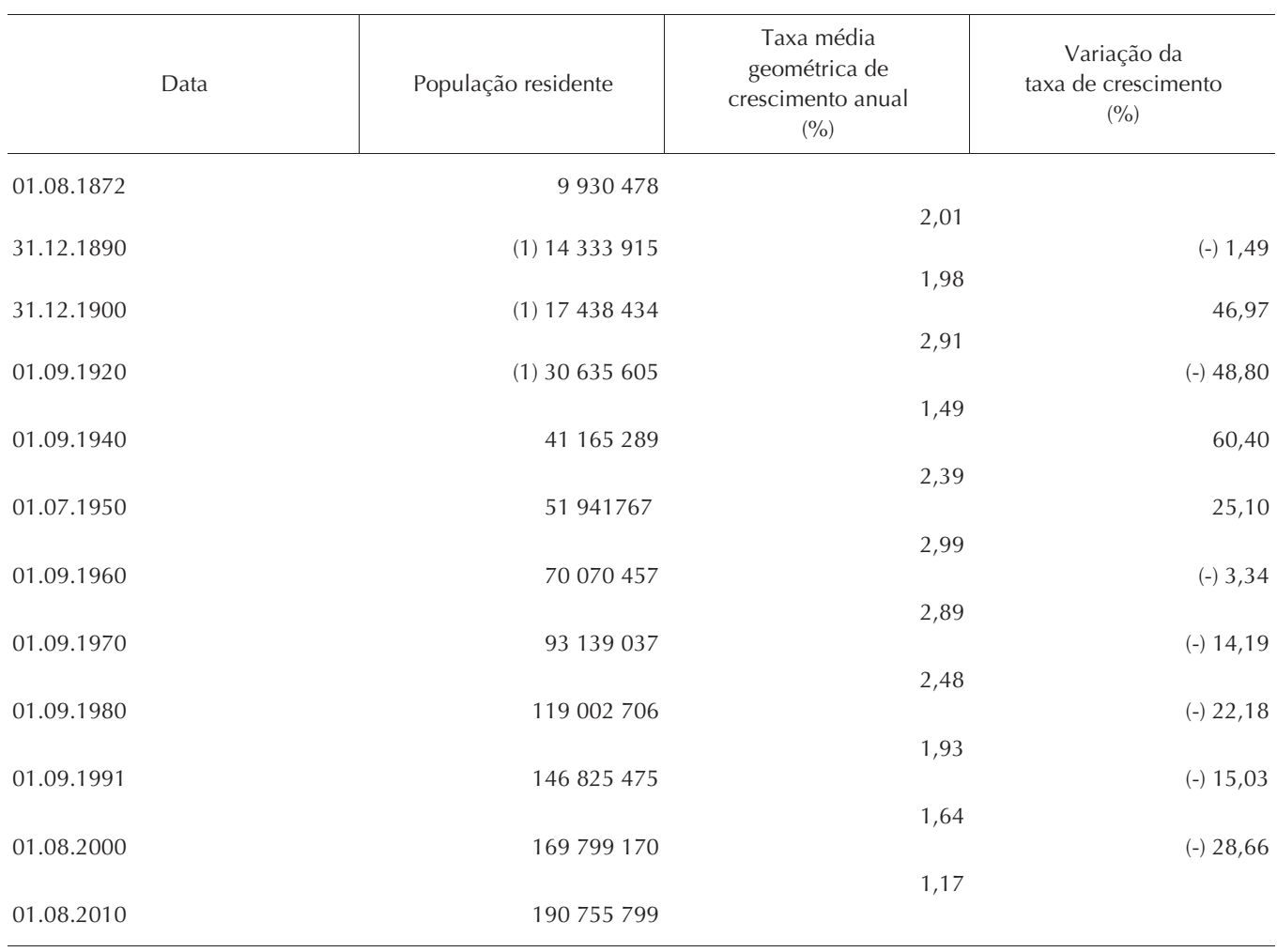

Fontes: 1. Directoria Geral de Estatística, Recenseamento do Brazil 1872/1920. 2. IBGE, Censo Demográfico 1940/2010.

(1) O efetivo populacional até o Censo de 1920 refere-se à população presente.

As Regiões Sul e Centro-Oeste, a partir de meados da década de 1970, também começam a se urbanizar de forma intensa, apesar da expansão das atividades agrícolas nestas áreas. O crescimento urbano coexiste com uma atividade agrícola muito intensa, passando por um processo de modernização no transcorrer das últimas décadas e favorecendo o processo de expulsão populacional do campo para as cidades, inclusive em áreas que até os anos 1960 e 1970 representavam espaços de expansão da fronteira agrícola.

Por outro lado, nas Regiões Norte e Nordeste, os níveis de urbanização ainda em 2010 são relativamente mais baixos $(73,0 \%)$, quando confrontados com os das Regiões Sudeste $(92,9 \%)$, Centro-Oeste $(88,8 \%)$ e Sul $(84,9 \%)$ (Tabela 2 e Gráfico 1$)$. 
Tabela 2 - Taxas de urbanização, segundo as Grandes Regiões - 1940/2010

\begin{tabular}{l|r|r|r|r|r|r|r|r}
\hline \multirow{2}{*}{ Grandes Regiões } & \multicolumn{7}{c}{ Taxa de urbanização (\%) } \\
\cline { 2 - 9 } & 1940 & 1950 & 1960 & 1970 & 1980 & 1991 & 2000 & 2010 \\
\hline \multirow{2}{*}{ Brasil } & $\mathbf{3 1 , 2}$ & $\mathbf{3 6 , 2}$ & $\mathbf{4 4 , 7}$ & $\mathbf{5 5 , 9}$ & $\mathbf{6 7 , 6}$ & $\mathbf{7 5 , 6}$ & $\mathbf{8 1 , 2}$ & $\mathbf{8 4 , 4}$ \\
Norte & 27,7 & 31,5 & 37,4 & 45,1 & 51,6 & 59,0 & 69,9 & 73,5 \\
Nordeste & 23,4 & 26,4 & 33,9 & 41,8 & 50,5 & 60,7 & 69,1 & 73,1 \\
Sudeste & 39,4 & 47,5 & 57,0 & 72,7 & 82,8 & 88,0 & 90,5 & 92,9 \\
Sul & 27,7 & 29,5 & 37,1 & 44,3 & 62,4 & 74,1 & 80,9 & 84,9 \\
Centro Oeste & 21,5 & 24,4 & 34,2 & 48,0 & 67,8 & 81,3 & 86,7 & 88,8 \\
\hline
\end{tabular}

Fonte: IBGE, Censo Demográfico 1940/2010.

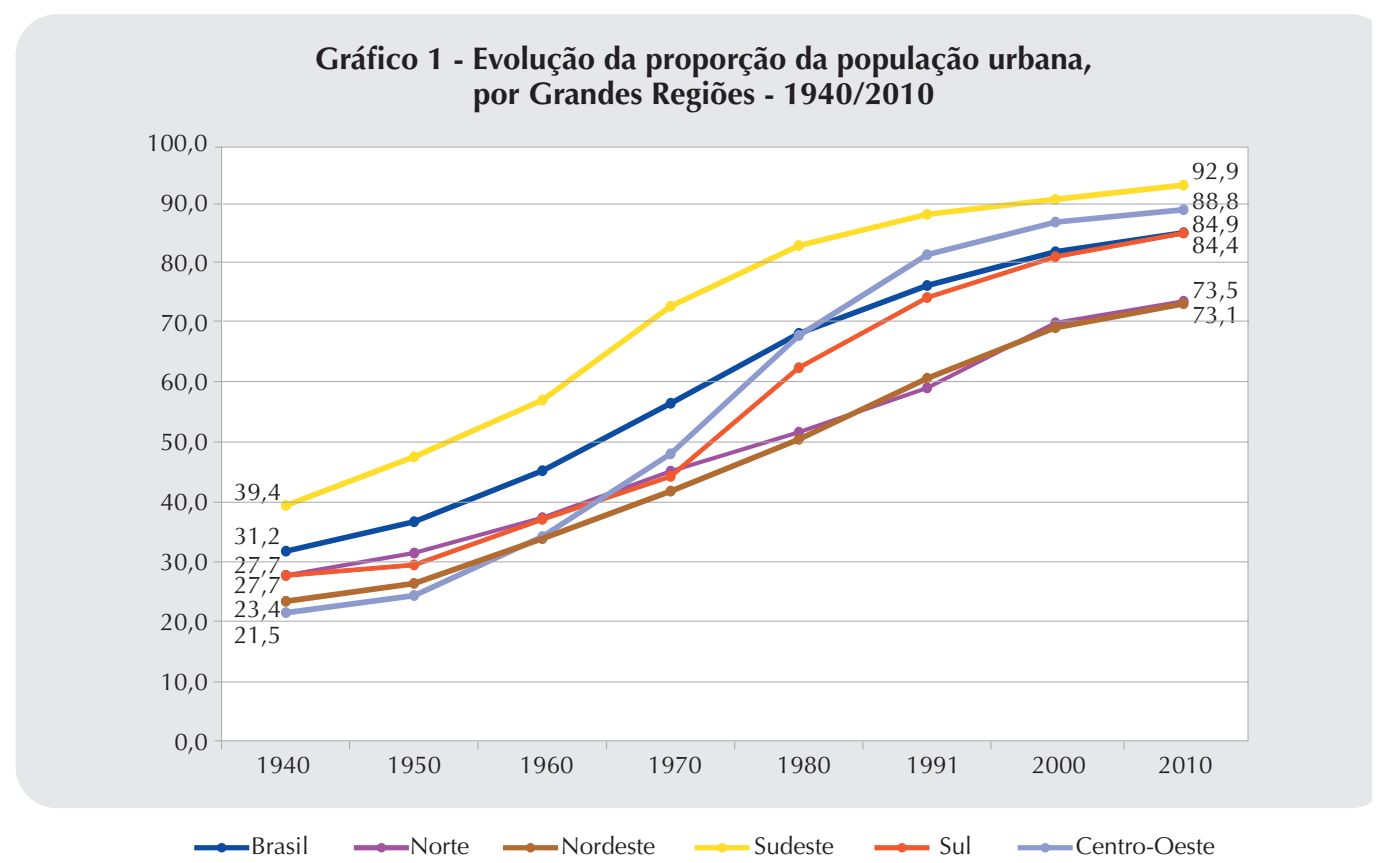

Fonte: IBGE, Censo Demográfico 1940/2010.

Em síntese, pode-se assegurar que o Brasil passou por profundas alterações durante as últimas décadas, ao deixar de ser um País predominantemente rural, situação que prevaleceu até meados da década de 1960, para uma condição atual em que $84,4 \%$ de sua população já reside em áreas urbanas.

Uma análise mais detalhada do comportamento demográfico, no Brasil, leva-se a concluir que o mesmo se manteve estável até meados do Século XX, com leves declínios da mortalidade e períodos de elevação cíclica da imigração estrangeira. Os níveis de natalidade e de mortalidade permaneceram, com pequenas oscilações, em patamares elevados, com a mortalidade apresentando tênues e graduais reduções, já a partir do final do Século XIX, enquanto que os níveis de fecundidade iniciavam declínios, embora menos expressivos, em algumas regiões específicas, a partir do início do século seguinte.

Vale ressaltar que os valores mais elevados das taxas brutas de natalidade, que oscilavam entre 45 e 50 nascimentos por 1000 habitantes, e das taxas de fecundidade total, 
que variavam, em média, entre sete e nove filhos, por mulher, refletiam a prevalência, no período, de uma visão de família numerosa, típica de sociedades agrárias precariamente urbanizadas e industrializadas.

Transformações mais consistentes no padrão demográfico só se iniciam a partir de meados da década de 1940, decorrentes, num estágio inicial, de uma relativa aceleração do declínio da mortalidade, conforme será detalhado a seguir.

Acompanhando ao longo do tempo as variáveis componentes da decomposição da taxa de crescimento demográfico ${ }^{2}$ - taxas brutas de natalidade e de mortalidade - estimadas para o Brasil, chama a atenção o fato de a mortalidade registrar declínio consistente a partir de 1940, apresentando-se estável nos períodos anteriores e com leves reduções no início do Século XX. Fundamental ressaltar o papel dos antibióticos nesse processo de queda, influenciando, num primeiro momento, na redução da mortalidade adulta, e, posteriormente, na redução da mortalidade dos grupos etários infantis e infantojuvenis.

A natalidade, por outro lado, inicia de forma mais consolidada seu declínio somente a partir dos anos 1960, acompanhando as grandes transformações socioeconômicas que vinham acontecendo no País, principalmente nas regiões do Centro-Sul, além da intensificação do processo de urbanização decorrente, em parte, dos intensos deslocamentos populacionais de origem rural, para os centros urbanos. Além do mais, esse período foi coincidente com a introdução da pílula anticoncepcional que operou como importante ferramenta na redução do tamanho da família e, posteriormente, a partir do final da década de 1970, com a prática da esterilização, iniciada especialmente nos estados da Região Sudeste e estendida aos da Região Nordeste, a partir de meados da década de 1980.

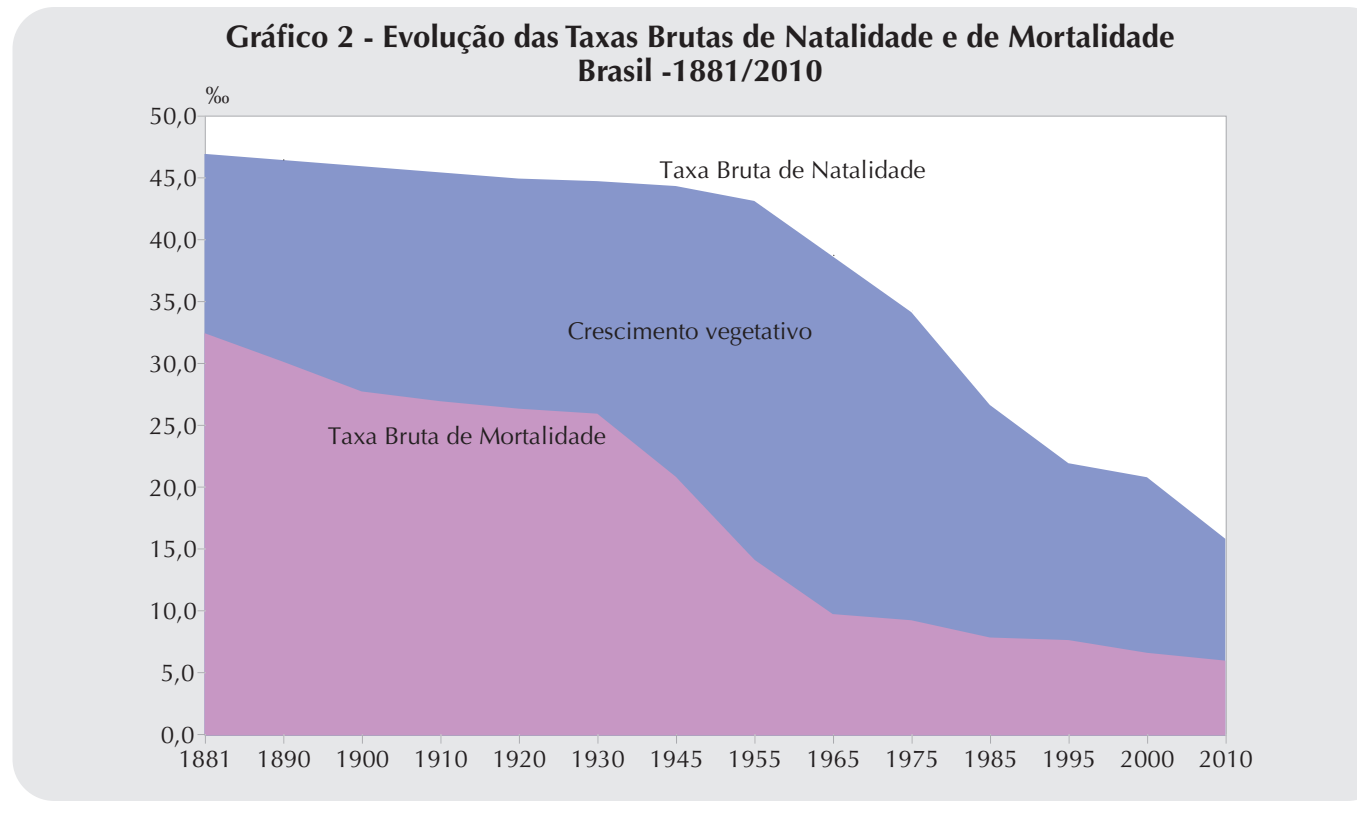

Fontes: 1. Directoria Geral de Estatística, Recenseamento do Brazil 1872/1920. 2. IBGE, Censo Demográfico 1940/2010 e Projeção da População do Brasil por Sexo e Idade 2000-2060.

\footnotetext{
2 Em termos conceituais, crescimento demográfico é resultante da diferença entre nascimentos e óbitos, mais os efeitos líquidos dos saldos migratórios.
} 
O auge do crescimento demográfico brasileiro ocorreu na década de 1950, quando foi mais elevada a diferença entre a natalidade e a mortalidade, com o País crescendo cerca de $3,0 \%$ ao ano.

A partir da análise do Censo Demográfico 1991, observa-se que, na década anterior, foi intensificado o declínio dos níveis de natalidade. Nesse período, a estimativa da taxa bruta de natalidade, que era, em média, de 29,0 nascimentos por 1000 habitantes (1985), declina para, percentualmente, 20,9\%, no ano 2000, e 15,9\%, em 2010. Em paralelo, as taxas brutas de mortalidade decaem mais lentamente, nas últimas décadas, pois seus patamares já eram relativamente baixos, oscilando apenas em função de comportamentos específicos por idade 3 .

Em síntese, a componente natalidade e os padrões correlatos de fecundidade são os principais agentes de mudanças no padrão demográfico brasileiro. O seu movimento de declínio é que explica a razão pela qual a taxa de crescimento demográfico registrada no Brasil é inferior, atualmente, a 1,2\% ao ano, de acordo com os resultados da população recenseada em 2010, quando comparados com os de 2000 (Tabela 1).

Uma análise mais detalhada dos parâmetros demográficos possibilita uma avaliação qualificada dos indicadores de mortalidade, especificamente, aqueles relativos à esperança de vida ao nascer, além de indicadores do comportamento reprodutivo (taxas de fecundidade total). Dada a grande diferenciação regional que caracteriza o Brasil, um entendimento correto dos processos demográficos, não pode deixar de incorporar a diversidade regional, conforme será visto no decorrer dos próximos capítulos.

\section{Esperança de vida ao nascer}

Raros são os estudos realizados no Brasil que permitem avaliar os níveis de sobrevivência até o início do Século XX, caso se considerar o indicador esperança de vida ao nascer. Cabe destacar, contudo, o estudo desenvolvido por Santos (1978) que, utilizando o modelo de populações estáveis, estimou a esperança de vida ao nascer da população brasileira para os anos de 1900, 1910, 1920 e 1930, cujas estimativas são apresentadas na Tabela 3.

De acordo com os resultados, pode-se concluir que, durante os primeiros 30 anos do Século XX, a população brasileira teve um aumento na sua sobrevivência de aproximadamente três anos, ou seja, um incremento de apenas $8,0 \%$, refletindo, portanto, uma elevada incidência de mortalidade, que só começou a diminuir a partir dos anos 1940. É importante também destacar a maior sobrevivência entre as mulheres, quando comparada com a dos homens. Ou seja, as diferenças que eram menores de 1 ano no início do Século XX, sobem para 1,6 ano, até 1930. Esta maior sobrevivência entre as mulheres continuará aumentando, conforme se verá mais adiante.

\footnotetext{
3 Tais como os relativos à redução da mortalidade infantil e infantojuvenil e o novo perfil epidemiológico, como, por exemplo, o aumento da mortalidade por causas externas etc.
} 
Tabela 3 - Evolução da esperança de vida ao nascer, por sexo - Brasil - 1900/1930

\begin{tabular}{|c|c|c|c|c|}
\hline \multirow{2}{*}{ Ano } & \multicolumn{3}{|c|}{ Esperança de vida ao nascer $\left(\mathrm{e}_{0}\right)$} & \multirow{2}{*}{$\begin{array}{c}\text { Diferença na }\left(\mathrm{e}_{0}\right) \\
\text { entre mulheres e homens }\end{array}$} \\
\hline & Total & Homens & Mulheres & \\
\hline 1900 & 33,65 & 33,28 & 34,05 & 0,77 \\
\hline 1910 & 34,08 & 33,55 & 34,62 & 1,07 \\
\hline 1920 & 34,51 & 33,84 & 35,21 & 1,37 \\
\hline 1930 & 36,49 & 35,72 & 37,29 & 1,57 \\
\hline
\end{tabular}

Fonte: Santos, J. L. F. Demografia: estimativas e projeções: medidas de fecundidade e mortalidade para o Brasil no século XX São Paulo: Universidade de São Paulo - USP, Faculdade de Arquitetura e Urbanismo: Fundação para Pesquisa Ambiental, 1978. (Cadernos de estudo e pesquisa do Prodeur).

A Tabela 4 e o Gráfico 3 exibem os valores desse indicador para os anos posteriores a meados da década de 1930 até 2014, para o País como um todo e suas Grandes Regiões. É indiscutível a melhoria nos níveis de sobrevivência da população brasileira a partir de meados da década de 1930, quando a média de anos de vida foi estimada em 41,5 anos, passando para 45,5 anos, em meados da década de 1940. Ou seja, os ganhos foram de quatro anos, elevando-se para mais de seis anos no período de 1945 a 1955. Entre 1955 e 1965, observou-se desaceleração no número de anos de vida (1,8 ano).

As diferenças regionais já se refletiam nos distintos níveis de sobrevivência entre as populações residentes no País. Enquanto a Região Nordeste, durante a década de 1930/1940, apresentava os menores valores de esperança de vida ao nascer (36,7 anos), este indicador era de 49,2 anos, na Sul; 47,9 anos, na Centro-Oeste, e 43,5 anos, na Sudeste. Estas diferenças regionais refletem, entre outros fatores, a prioridade dos investimentos econômicos então norteados para as Regiões Sudeste e Sul do País, em detrimento da Região Nordeste, que, em decorrência, se transforma em área de expulsão populacional.

Tabela 4 - Esperança de vida ao nascer, segundo as Grandes Regiões - 1930/2014

\begin{tabular}{l|c|c|c|c|c|c|c|c|c}
\hline \multirow{2}{*}{$\begin{array}{c}\text { Grandes } \\
\text { Regiões }\end{array}$} & \multicolumn{10}{c}{ Esperança de vida ao nascer (anos) } \\
\cline { 2 - 11 } & $\begin{array}{c}1930 / \\
1940\end{array}$ & $\begin{array}{c}1940 / \\
1950\end{array}$ & $\begin{array}{c}1950 / \\
1960\end{array}$ & $\begin{array}{c}1960 / \\
1970\end{array}$ & 1980 & 1991 & 2000 & 2010 & 2014 \\
\hline \multicolumn{1}{c}{ Brasil } & $\mathbf{4 1 , 5 3}$ & $\mathbf{4 5 , 5 1}$ & $\mathbf{5 1 , 6 4}$ & $\mathbf{5 3 , 4 6}$ & $\mathbf{6 2 , 5 2}$ & $\mathbf{6 6 , 9 3}$ & $\mathbf{7 0 , 4 4}$ & $\mathbf{7 3 , 8 6}$ & $\mathbf{7 5 , 4 4}$ \\
Norte & 40,69 & 44,59 & 53,36 & 54,63 & 60,75 & 66,92 & 69,53 & 70,79 & $\mathbf{7 2 , 0 0}$ \\
Nordeste & 36,68 & 38,94 & 40,98 & 45,54 & 58,25 & 62,83 & 67,15 & 71,23 & $\mathbf{7 2 , 5 1}$ \\
Sudeste & 43,53 & 48,95 & 57,18 & 57,30 & 64,82 & 68,83 & 71,99 & 75,55 & 76,89 \\
Sul & 49,19 & 52,82 & 60,32 & 60,03 & 66,01 & 70,40 & 72,74 & 75,87 & 77,19 \\
Centro-Oeste & 47,92 & 51,11 & 56,65 & 58,93 & 62,85 & 68,55 & 71,75 & 73,69 & 74,67 \\
\hline
\end{tabular}

Fonte: IBGE, Censo Demográfico 1940/2010 e Projeção da População das Unidades da Federação por Sexo e Idade 2000-2030. 
Importante também mencionar o impulso dado ao sistema de saúde pública, à previdência social, à infraestrutura urbana e à regulamentação do mercado de trabalho, observado principalmente nas regiões do Centro-Sul do País, e relacionado com o processo de urbanização nestas áreas, iniciado a partir dos anos 1930. Esses fatores institucionais, agregados aos avanços da indústria químico-farmacêutica, permitiram o controle e a redução de várias doenças, sobretudo as infectocontagiosas e pulmonares que até então tinham forte incidência sobre a população, com altos níveis de letalidade. Este conjunto de ações atuou positivamente na melhoria da qualidade de vida da população, elevando seus anos de vida média ao nascer. Ou seja, até meados da década de 1950, a esperança de vida ao nascer aumentou cerca de 10 anos para o País como um todo, ao passar de 41,5 anos (1930/1940) para 51,6 anos (1950/1960), porém, de forma menos acentuada na Região Nordeste, que teve um incremento de apenas 4,3 anos, enquanto, nas regiões do Centro-Sul, os ganhos alcançaram a cifra de 13,7 anos, a exemplo da Região Sudeste. Estes maiores ganhos, certamente, são decorrentes das ações anteriormente descritas.

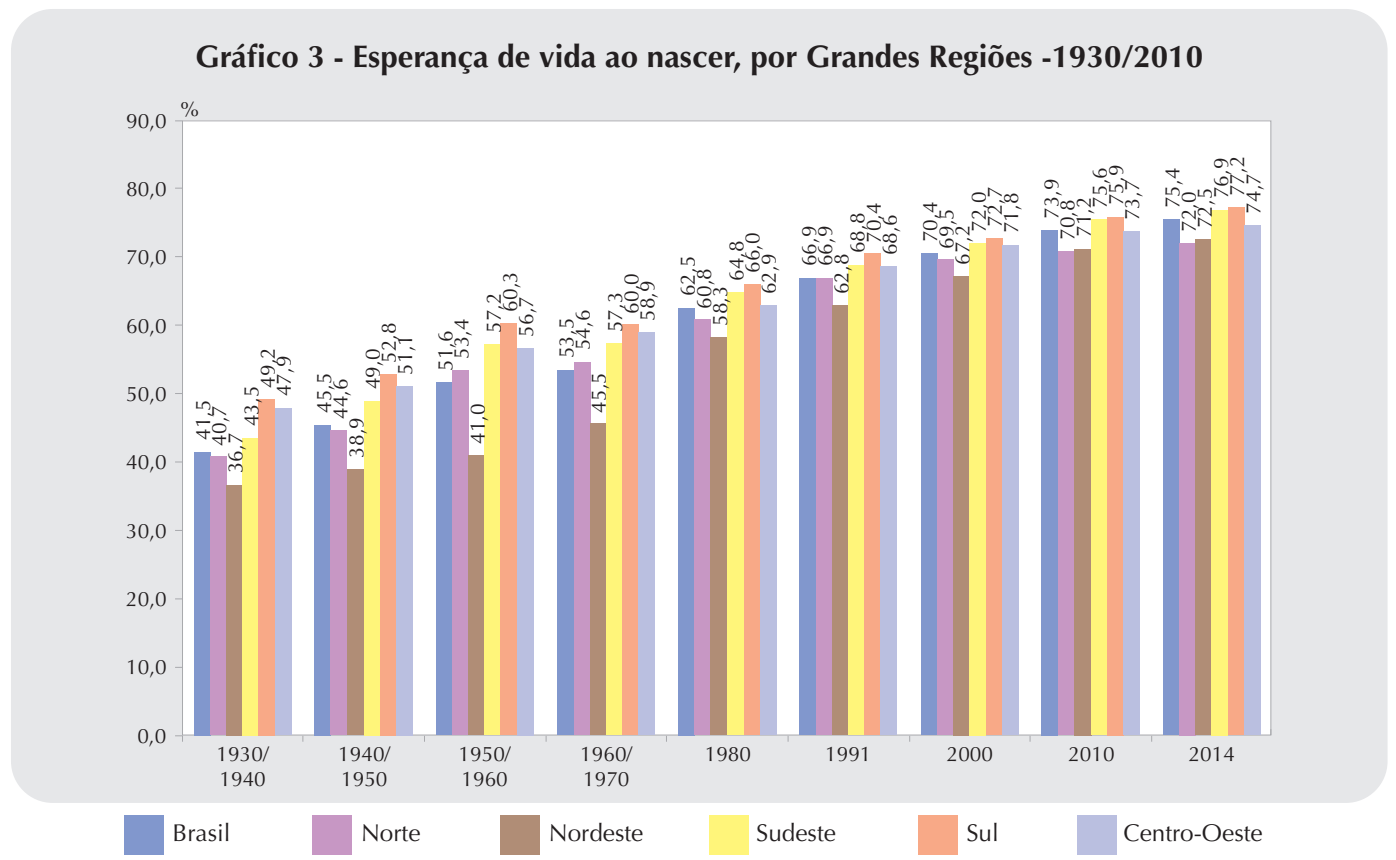

Fonte: IBGE, Censo Demográfico 1940/2010 e Projeção da População das Unidades da Federação por Sexo e Idade $2000-2030$.

Ainda com base nas informações da Tabela 4 e do Gráfico 3, constata-se que, de 1955 até o início da década de 1970, esse processo de aumento da esperança de vida ao nascer prossegue, todavia, de forma mais lenta, o que mostra a sensibilidade desse indicador ao contexto socioeconômico mais amplo. Ou seja, na ausência de políticas estruturadas e compensatórias direcionadas para a melhoria e a preservação das condições de saúde da população, em particular, a infantil, os agravos econômicos impactam, de maneira mais acentuada, exatamente aqueles segmentos populacionais que se encontram fragilizados. Em 
termos regionais, observa-se que, nas Regiões Sudeste e Sul, a esperança de vida ao nascer, praticamente, se manteve inalterada, em torno de 57 e 60 anos, respectivamente. Durante esse mesmo período, melhoraram as condições de sobrevivência da população nordestina, com incrementos de cinco anos, embora mantendo ainda valores bem abaixo dos observados para aquelas mesmas regiões.

No período de 1965 a 1975, foram constatados os menores ganhos na mortalidade, sobretudo, nas Regiões Sudeste e Sul, justamente por serem essas regiões o núcleo hegemônico da economia nacional e, portanto, diretamente mais expostas aos efeitos das flutuações na conjuntura econômica.

A crise estrutural, notadamente em suas dimensões econômico-institucional, pela qual passava a sociedade brasileira naquele período, foi talvez a principal causa da interrupção do processo de declínio da mortalidade. Cabe lembrar ainda que o grande êxodo populacional rural e a pressão demográfica sobre os grandes centros urbanos foram muito marcantes durante a década e representaram uma pressão adicional sobre os serviços de infraestrutura e de atendimento público (O PROCESSO..., 1998).

Foi a partir de meados da década de 1970, contudo, que se retomou a tendência de queda da mortalidade, tanto a geral como a infantil, em todos os países da América Latina. No caso específico do Brasil, a retomada do processo de declínio da mortalidade esteve associada, no âmbito das políticas centralizadoras do regime militar, às ações representadas pela expansão da rede assistencial e à ampliação da infraestrutura de saneamento básico, sobretudo, da rede de abastecimento d'água, a qual teve o papel principal na continuidade do processo (VETTER; SIMÕES, 1981).

Em decorrência da ampliação da oferta dos serviços de saúde e de saneamento básico e do avanço da escolarização, iniciou-se redução significativa nos padrões históricos da desigualdade regional diante da morte no País. A Região Nordeste apresentou os maiores aumentos da esperança de vida ao nascer durante o período de 1975 a 2014. A ampliação dos serviços de saneamento básico, em áreas até então excluídas, os programas de saúde materno-infantil, sobretudo os voltados para o pré-natal, parto e puerpério, a ampliação da oferta de serviços médico-hospitalares, as campanhas de vacinação, os programas de aleitamento materno e reidratação oral, em muito contribuíram para a continuidade da redução dos níveis de mortalidade infantil e infantojuvenil, principalmente a partir dos anos 1980 (SIMÕES, 1997).

Este conjunto de ações, que atuaram no sentido de reduzir a mortalidade infantil e na infância, foi um dos fatores centrais relacionados com o incremento da esperança de vida ao nascer, principalmente na Região Nordeste, conforme estudo desenvolvido no âmbito da Rede Interagencial de Informações para a Saúde - RIPSA, divulgado pela Organização Pan-Americana da Saúde - OPAS (SIMÕES, 2002). Ou seja, considerando o indicador esperança de vida ao nascer, as diferenças regionais, que eram elevadas durante a maior parte do período analisado, reduziram-se significativamente até o início da segunda década do Século XXI. Exemplificando, as diferenças entre as Regiões Nordeste e Sul, que eram de 19,3 anos, no período de 1950-1960, baixam para 4,7 anos, em 2014 (Tabela 4). 
Outro aspecto relacionado com este indicador refere-se aos diferenciais de sobrevivência por sexo (Tabela 5). Historicamente, essas diferenças não eram importantes, mas, a partir dos anos 1980, passam a adquirir significância em praticamente todas as regiões brasileiras, resultado da tendência de aumento das causas violentas que passam a afetar prioritariamente o sexo masculino, de tal forma que sua incidência chega a ser mais que o triplo, em relação ao sexo feminino (SIMÕES, 2016).

Em 1980, enquanto a esperança de vida ao nascer para o sexo feminino era de 65,7 anos, para o masculino, o valor foi de 59,6 anos. Ou seja, em nível nacional, as mulheres tinham uma sobrevida de seis anos em relação aos homens.

Em decorrência do agravamento da violência no sexo masculino, durante os períodos seguintes, particularmente nas faixas etárias que compõem o grupo de jovens-adultos (15 a 29 anos de idade), a diferença na esperança de vida ao nascer entre os sexos, para o Brasil, aumentou para 7,9 anos, em 2000, sendo que, na Região Sudeste, esse valor era de 8,6 anos inferior à das mulheres, seguida pelas Regiões Norte ( 8,3 anos), Nordeste ( 7,8 anos) e Sul $(7,0$ anos). Entre 2000 e 2010, enquanto, nas Regiões Nordeste e Centro-Oeste, observaram-se tendências de aumento dessas diferenças, nas demais regiões ocorreu o oposto. Entretanto, é importante chamar a atenção para o fato de que, na Região Sudeste, apesar da diminuição observada na esperança de vida ao nascer, as diferenças ainda continuam elevadas.

Tabela 5 - Esperança de vida ao nascer, por sexo, segundo as Grandes Regiões - 1980/2014

\begin{tabular}{|c|c|c|c|c|c|c|c|c|c|}
\hline \multirow{3}{*}{$\begin{array}{l}\text { Grandes } \\
\text { Regiões }\end{array}$} & \multicolumn{9}{|c|}{ Esperança de vida ao nascer } \\
\hline & \multicolumn{3}{|c|}{1980} & \multicolumn{3}{|c|}{1991} & \multicolumn{3}{|c|}{2000} \\
\hline & Total & Homens & Mulheres & Total & Homens & Mulheres & Total & Homens & Mulheres \\
\hline Brasil & \multicolumn{3}{|l|}{62,52} & \multicolumn{2}{|l|}{66,93} & 70,90 & 70,44 & 66,71 & 74,35 \\
\hline Norte & 60,75 & 58,18 & 63,74 & 66,92 & 63,67 & 70,33 & 69,53 & 66,82 & 72,38 \\
\hline Nordeste & 58,25 & 55,40 & 61,27 & 62,83 & 59,56 & 66,27 & 67,15 & 63,60 & 70,88 \\
\hline Sudeste & 64,82 & 61,68 & 68,23 & 68,83 & 64,46 & 73,42 & 71,99 & 67,90 & 76,28 \\
\hline Sul & 66,01 & 63,26 & 69,07 & 70,40 & 66,69 & 74,30 & 72,74 & 69,39 & 76,26 \\
\hline Centro-Oeste & \multicolumn{2}{|l|}{62,85} & 65,60 & 68,55 & 65,22 & 72,04 & 71,75 & 68,36 & 75,31 \\
\hline & & & perança de $v$ & la ao nasc & & & & & \\
\hline $\begin{array}{l}\text { Urandes } \\
\text { Regiões }\end{array}$ & & 2010 & & & 2014 & & & & \\
\hline & Total & Homens & Mulheres & Total & Homens & Mulheres & Total & Homens & Mulheres \\
\hline Brasil & 73,86 & 70,21 & 77,60 & 75,14 & 71,57 & 78,78 & 12,62 & 11,95 & 13,09 \\
\hline Norte & 70,79 & 68,58 & 74,44 & 71,77 & 68,45 & 75,53 & 11,02 & 10,27 & 11,79 \\
\hline Nordeste & 71,23 & 67,17 & 75,47 & 72,51 & 68,40 & 76,75 & 14,26 & 13,00 & 15,48 \\
\hline Sudeste & 75,55 & 72,06 & 79,00 & 76,89 & 73,62 & 80,10 & 12,07 & 11,94 & 11,87 \\
\hline Sul & 75,87 & 72,46 & 79,33 & 77,19 & 73,80 & 80,60 & 11,18 & 10,54 & 11,53 \\
\hline Centro-Oeste & 73,69 & 70,44 & 77,20 & 74,67 & 71,39 & 78,17 & 11,82 & 10,88 & 12,57 \\
\hline
\end{tabular}

Fonte: IBGE, Censo Demográfico 1980/2010 e Projeção da População das Unidades da Federação por Sexo e Idade $2000-2030$. 
Todavia, apesar das perdas observadas no indicador, particularmente entre os homens, é importante ressaltar os ganhos nos valores da esperança de vida ao nascer, em cada sexo, durante o período de 1980 a 2014, alcançando 12,0 anos para os homens e 13,1 anos entre as mulheres, no País como um todo. As Regiões Nordeste (13,0 anos), Sudeste (11,9 anos) e Centro-Oeste (10,9 anos) foram as Grandes Regiões onde se notaram os maiores ganhos na esperança de vida ao nascer, entre os homens. Por outro lado, entre as mulheres, os maiores incrementos foram verificados na Região Nordeste (15,5 anos), seguida pela Centro-Oeste (12,6 anos), Sudeste (11,9 anos) e Norte (11,8 anos). Não obstante, apesar de os maiores avanços na esperança de vida ao nascer terem se verificado nas Regiões Nordeste e Norte, é, contudo, fundamental salientar que as Regiões Sudeste, Sul e Centro-Oeste ainda exibem os valores mais elevados da esperança de vida ao nascer, independentemente do sexo ${ }^{4}$.

Em síntese, os dados sobre o aumento da esperança de vida ao nascer e os impactos da forte redução da fecundidade, conforme será discutido no próximo tópico, apontam claramente para um processo de envelhecimento populacional no País, o que vai exigir novas prioridades na área das políticas públicas. Como exemplo dessas prioridades, destaca-se, dentro de um plano, a formação urgente de recursos humanos para o atendimento geriátrico e gerontológico, além de providências a serem adotadas com relação à previdência social, que deverá se adequar a essa nova configuração demográfica, além de melhorias urgentes nas redes de atendimento hospitalar, ajustando-as a esta nova configuração populacional que tende a um crescimento cada vez mais intenso.

A não adequação da estrutura de saúde e econômica a essa nova realidade, por certo, trará efeitos negativos sobre a qualidade de vida da população brasileira que está vivenciando o processo de transição, onde, em curto e médio prazos, os idosos serão a grande maioria, com necessidades altamente diferenciadas em relação à situação anterior.

Paralelamente ao aumento da esperança de vida ao nascer, também serão discutidas as alterações que vêm se sucedendo nos níveis de reprodução das mulheres brasileiras, que vêm apresentando fortes declínios no decorrer das últimas duas décadas e que também são responsáveis pelo processo de envelhecimento por que vem passando a sociedade brasileira. No entanto, antes de se focar esse tema específico, relacionado com o processo de reprodução da mulher brasileira, será analisado o histórico da mortalidade infantil observado no Brasil, tendo em vista sua vinculação com a esperança de vida ao nascer.

\section{A evolução das taxas de mortalidade infantil $\left.\right|^{5}$}

Outra variável que vem experimentando alterações intensas, no Brasil, numa perspectiva altamente positiva, é a mortalidade infantil.

\footnotetext{
4 Para maiores detalhes do impacto da violência sobre a mortalidade em jovens, ver texto de Simões (1997).

5 Conceitualmente, a taxa de mortalidade infantil é a relação entre o número de óbitos de menores de 1 ano de idade, por 1000 nascidos vivos, na população residente em determinado espaço geográfico, no ano considerado. Estima o risco de morte dos nascidos vivos durante o seu primeiro ano de vida.
} 
Uma visão geral do quadro da evolução da mortalidade infantil é apresentada na Tabela 6 e no Gráfico 4, considerando o País como um todo e cada uma das Grandes Regiões, a partir dos anos 1930. A configuração de distintas trajetórias da mortalidade infantil entre as regiões brasileiras é um fato incontestável. Enquanto as Regiões Centro-Oeste, Sudeste e Norte mostravam, já antes de 1940, tendências lentas de declínio da mortalidade, a Região Nordeste e, principalmente, a Região Sul apresentavam níveis estáveis, com a diferença fundamental de que, nesta última, por razões históricas relacionadas com a colonização, com a importante contribuição dos fluxos de imigrantes europeus na sua estrutura populacional, seus níveis eram significativamente menores.

Na Região Nordeste, por exemplo, somente ao final da década de 1940, começa a se observar tendências na redução da mortalidade infantil, mesmo assim, num ritmo inferior ao das demais regiões.

Pode ser notada, com pequenas variações, a estabilidade dos níveis de mortalidade durante o período de 1955 a 1970, reflexo da crise estrutural, em suas dimensões econômica e institucional, passada pela sociedade brasileira, durante aquele período.

Tabela 6 - Taxas de mortalidade infantil, por Grandes Regiões - 1930/2014

\begin{tabular}{|c|c|c|c|c|c|c|}
\hline \multirow{2}{*}{ Ano } & \multicolumn{6}{|c|}{ Taxas de mortalidade infantil } \\
\hline & Brasil & Norte & Nordeste & Sudeste & Sul & Centro-Oeste \\
\hline 1930 & 162,4 & 193,3 & 193,2 & 153,0 & 121,0 & 146,0 \\
\hline 1935 & 152,7 & 170,0 & 188,0 & 145,0 & 120,0 & 133,0 \\
\hline 1940 & 150,0 & 166,0 & 187,0 & 140,0 & 118,0 & 133,0 \\
\hline 1945 & 144,0 & 156,0 & 185,0 & 130,0 & 113,0 & 123,0 \\
\hline 1950 & 135,0 & 145,4 & 175,0 & 122,0 & 109,0 & 119,0 \\
\hline 1955 & 128,2 & 127,5 & 169,6 & 108,0 & 94,7 & 114,0 \\
\hline 1960 & 124,0 & 122,9 & 164,1 & 110,0 & 96,0 & 115,0 \\
\hline 1965 & 116,0 & 111,3 & 153,5 & 96,0 & 84,0 & 99,0 \\
\hline 1970 & 115,0 & 104,3 & 146,4 & 96,2 & 81,9 & 89,7 \\
\hline 1975 & 100,0 & 94,0 & 128,0 & 86,0 & 72,0 & 77,0 \\
\hline 1980 & 80,1 & 68,4 & 116,3 & 53,8 & 46,0 & 54,2 \\
\hline 1985 & 64,1 & 57,8 & 98,0 & 41,7 & 36,4 & 44,1 \\
\hline 1990 & 48,0 & 45,9 & 75,8 & 31,4 & 28,3 & 34,3 \\
\hline 1995 & 35,7 & 35,4 & 55,5 & 24,2 & 22,5 & 26,8 \\
\hline 2000 & 29,0 & 31,0 & 45,2 & 20,1 & 16,9 & 22,6 \\
\hline 2005 & 22,2 & 25,2 & 32,0 & 16,1 & 14,0 & 19,7 \\
\hline 2010 & 17,2 & 21,1 & 23,1 & 13,0 & 11,6 & 17,0 \\
\hline 2014 & 14,4 & 18,6 & 18,4 & 11,5 & 10,1 & 15,2 \\
\hline
\end{tabular}

Fonte: IBGE, Censo Demográfico 1940/2010 e Projeção da População das Unidades da Federação por Sexo e Idade $2000-2030$.

As Regiões Sudeste e Sul foram as mais afetadas, inclusive com aumentos da mortalidade infantil, durante o período de 1955 a 1960 e de 1965 a 1970, decorrente dos seguintes fatores:

- Substancial redução do poder de compra do salário mínimo, que caiu em cerca de $45 \%$ durante o período de 1959 a 1974; 
- Profunda concentração de renda, que foi uma característica que acompanhou a evolução da economia brasileira; e

- Deterioração de certos serviços básicos, a exemplo do saneamento, relacionados com o forte impacto do aumento dos deslocamentos populacionais das áreas rurais para as urbanas.

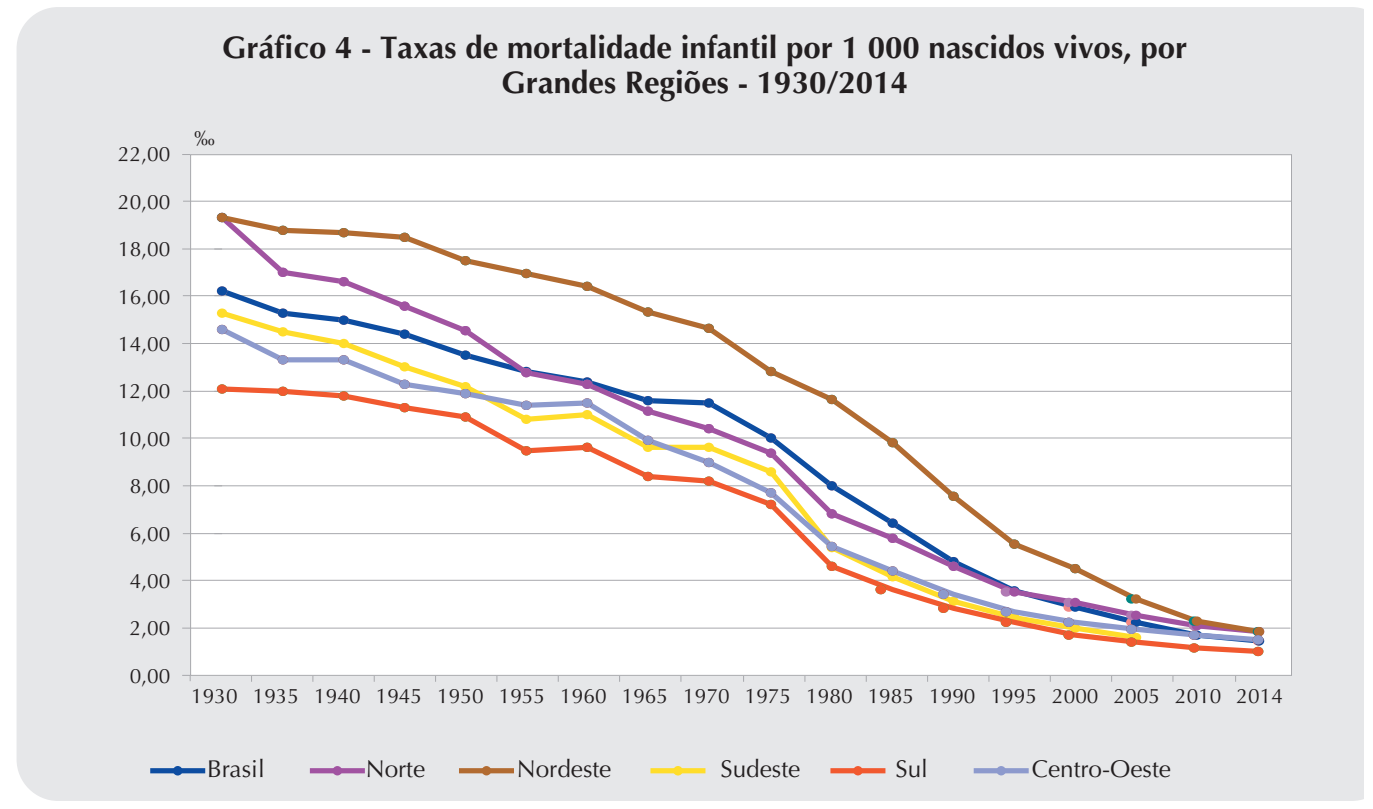

Fonte: IBGE, Censo Demográfico 1940/2010 e Projeção da População das Unidades da Federação por Sexo e Idade $2000-2030$.

É importante destacar que as diferenças regionais entre a mortalidade infantil não eram muito acentuadas no passado, mantendo-se os diferenciais à medida que se evoluía ao longo do tempo. Entretanto, a trajetória da mortalidade nordestina, por apresentar velocidade de queda inferior à observada nas demais regiões, principalmente até o final da década de 1980, foi um dos principais fatores relacionados com o aumento do diferencial entre elas, indicando um afastamento, cada vez maior.

Só para exemplificar, ao se comparar os valores da mortalidade infantil nordestina com os valores referentes à Região Sul, os mais baixos do País, constata-se que as diferenças que eram de 60,0\%, em 1930, e mantidas próximas a esse patamar durante as décadas seguintes, começam a elevar-se (150,3\%), a partir dos anos 1980, chegando a 170,0\% até o final dessa mesma década. A Região Norte, embora, com intensidade menor, seguiu tendência similar, provavelmente, em decorrência dos intensos fluxos migratórios que se dirigiram inicialmente para sua área de fronteira, sobretudo, a partir dos últimos anos da década de 1970 e início de 1980. Posteriormente, com a saturação dessas áreas, tem início um processo de deslocamentos para as capitais e periferias urbanas da região, que, na ausência de investimentos na infraestrutura urbana, gerou uma deterioração dessas áreas, agravados pela ausência de criação de empregos na economia formal, com fortes implicações nas condições de vida e sobrevivência desses grupos populacionais. 
Por outro lado, em 1990, embora ainda elevados, se se considerar a média existente em países desenvolvidos, os indicadores das demais regiões do País já tendiam a níveis similares da mortalidade infantil, com valores em torno de 30,0\%. Todavia, durante a década de 1990, dá-se início a mudanças no quadro da mortalidade infantil, quando começam a se observar reduções importantes nos diferenciais entre as regiões. Para o Brasil como um todo, a mortalidade infantil declina de 48 óbitos por 1000 menores de 1 ano de idade (1990) para, percentualmente, 29,0\%, em 2000; 17,2\%o, em 2010; declinando para 14,4\%, em 2014, de acordo com as novas Projeções da População por Sexo e Idade, divulgadas pelo IBGE em 2013, ou seja, uma queda de aproximadamente 64\%, durante o período de 1990 a 2014.

Para um melhor entendimento do processo de redução da mortalidade infantil no País, importante mencionar que, após a divulgação dos resultados do Censo Demográfico 2000, foi realizado um amplo trabalho de pesquisa sobre as atividades que estavam sendo desenvolvidas pela Pastoral da Criança, da Conferência Nacional dos Bispos do Brasil - CNBB; pelo Programa Saúde da Família, do Ministério da Saúde; ee pelo Fundo das Nações Unidas para a Infância (United Nations Children's Fund - UNICEF), além de programas como Bolsa Família, do governo federal, junto às comunidades mais carentes, principalmente nos municípios da Região Nordeste, onde os níveis de mortalidade infantil apresentavam patamares mais elevados, quando comparados com as demais regiões brasileiras. O monitoramento das crianças desde o nascimento é um fato concreto e prioritário, concluindo-se, a partir das informações disponíveis, que começaram a ocorrer melhorias inquestionáveis nas condições de saúde e sobrevivência nas faixas etárias de crianças em idade infantil e na infância.

Um exemplo dessas melhorias foi retratado no inquérito designado Chamada Nutricional, realizado em 2005, pelo então Ministério do Desenvolvimento Social e Combate à Fome, em parceria com o Ministério da Saúde, prefeituras, governos estaduais, 12 universidades públicas e o UNICEF, que deu origem ao relatório Chamada nutricional: um estudo sobre a situação nutricional das crianças do semi-árido brasileiro, publicado em 2006. O resultado do inquérito mostrou que a desnutrição infantil na Região Semiárida, uma das mais pobres do País, vinha caindo de forma expressiva. O estudo revelou que 6,6\% das crianças com até 5 anos de idade que viviam na região sofriam de desnutrição crônica (déficit de altura). O índice era 11 pontos percentuais menor que o registrado em 1996, em pesquisa semelhante efetuada na Região Nordeste, quando o percentual era de 17,9\%. Foram avaliadas 17 mil crianças com até 5 anos de idade, de 307 municípios da Região Semiárida, composta por oito estados da Região Nordeste e do norte do Estado Minas Gerais. De acordo com a pesquisa, quanto maior a renda da família, menor era o índice de desnutrição infantil. Enquanto na classe " $E$ ", 10,0\% das crianças apresentavam quadro de desnutrição crônica, na classe " $D$ ", esse índice era de 6,8\% e, na classe "C", de 2,5\%. Entre as crianças das famílias que faziam menos de três refeições por dia, o índice de desnutrição crônica chegava a 16,4\%, três vezes maior do que o observado entre as crianças que faziam três refeições ou mais $(5,8 \%)$.

Os resultados dessas ações, sem dúvida, tiveram importantes impactos na redução dos níveis da mortalidade infantil, evidenciados quando se estima o indicador para o período de 1990 a 2014. 
A Região Nordeste, que apresentava uma taxa de mortalidade infantil altíssima, 75,8\%, no início da década de 1990, em 2000, o valor dessa taxa se reduz para 45,2\%, mantendo a tendência de queda durante a década $(23,1 \%$ ) , sendo que o valor projetado do indicador para 2014 é de 18,4\%o, ou seja, um declínio de 40,4\%, entre 1990 e 2000; de 48,9\%, entre 2000 e 2010; e de 20,3\%, entre 2010 e 2014 (Tabela 7).

Cabe observar que, apesar das maiores reduções nos níveis de mortalidade infantil se verificarem na Região Nordeste, esta ainda continua exibindo as maiores taxas do País, quando comparadas às demais. Por conseguinte, com vistas a nortear ações de políticas públicas com o objetivo de intensificação de uma maior velocidade na redução da mortalidade infantil na região como um todo, são exibidos na Tabela 8, para os anos de 1990, 2000, 2010 e 2014, os valores desse indicador para o Brasil e as Unidades da Federação, além de suas variações relativas (\%) para cada período decenal considerado.

Tabela 7 - Variação relativa das taxas de mortalidade infantil, segundo as Grandes Regiões 1990/2010

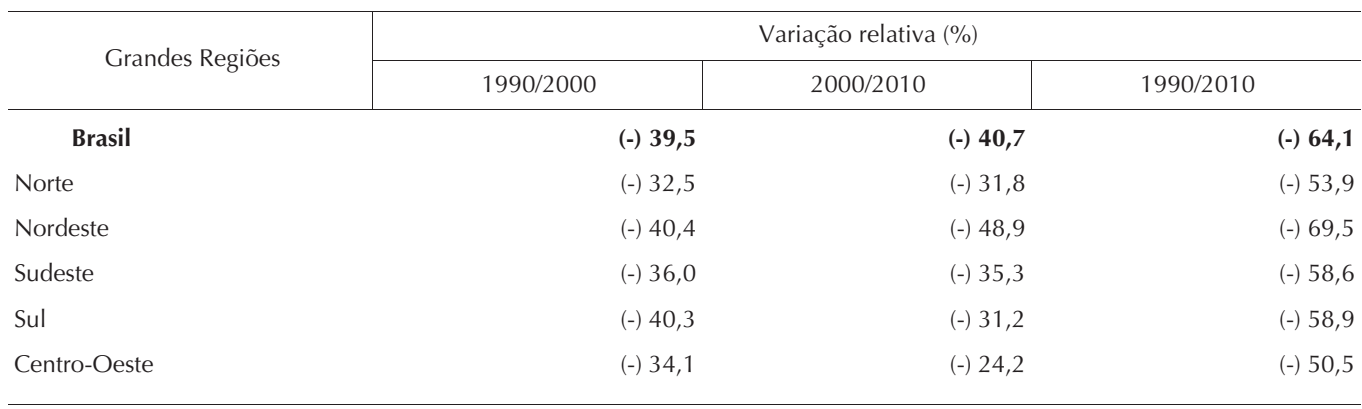

Fonte: IBGE, Censo Demográfico 1991/2010 e Projeção da População das Unidades da Federação por Sexo e Idade $2000-2030$.

Percebe-se que todas as Unidades da Federação que fazem parte das Regiões Norte e Nordeste, apesar de apresentarem intensa redução na mortalidade infantil no transcorrer das últimas duas décadas, revelam ainda níveis superiores à média nacional, sendo que os índices mais elevados, observados no ano de 2014, estão localizados no Amapá $(23,0 \%$ ), Rondônia (20,8\%) e Acre (18,4\%), estados da Região Norte; além do Maranhão (23,5\%), Alagoas $(22,4 \%$ ), Piauí $(20,4 \%$ ) e Bahia (19\%o), da Região Nordeste. Já as demais Unidades da Federação desta região apresentam valores abaixo desse patamar, a exemplo da Paraíba $(18,0 \%)$, Rio Grande do Norte (16,1\%o), Ceará (15,8\%o) e Pernambuco (14,0\%o).

Por outro lado, Espírito Santo (9,6\%), Santa Catarina (9,8\%), Paraná $(10,1 \%)$, Rio Grande do Sul (10,2\%o), São Paulo (10,5\%o), Distrito Federal (11,0\%o), Minas Gerais $(12,0 \%$ o) e Rio de Janeiro $(12,50 \%$ ) se destacam como as Unidades da Federação de menor mortalidade infantil, enquanto, em patamares intermediários, levemente acima da média nacional $(14,4 \%)$, as demais.

Uma visão deste quadro mais recente dos diferenciais de mortalidade infantil é sintetizada no Gráfico 5, que apresenta, para o ano de 2014, uma ordenação das taxas de mortalidade infantil por Grandes Regiões e Unidades da Federação. 
Tabela 8 - Taxas de mortalidade infantil, segundo as Unidades da Federação - 1990/2014

\begin{tabular}{|c|c|c|c|c|c|c|c|}
\hline \multirow{2}{*}{ Unidades da Federação } & \multicolumn{4}{|c|}{ Taxas de mortalidade infantil ( $\%$ ) } & \multicolumn{3}{|c|}{ Variação relativa (\%) } \\
\hline & 1990 & 2000 & 2010 & 2014 & $1990 / 2014$ & $2000 / 2010$ & $2010 / 2014$ \\
\hline Rondônia & 42,6 & 29,2 & 22,8 & 20,8 & 51,2 & 28,6 & 8,5 \\
\hline Acre & 56,5 & 38,0 & 22,1 & 18,4 & 67,5 & 51,7 & 16,8 \\
\hline Amazonas & 44,5 & 32,3 & 22,2 & 19,4 & 56,4 & 39,9 & 12,7 \\
\hline Roraima & 39,6 & 19,7 & 18,4 & 17,6 & 55,7 & 10,8 & 4,4 \\
\hline Pará & 46,2 & 30,1 & 20,3 & 17,7 & 61,8 & 41,4 & 13,0 \\
\hline Amapá & 38,1 & 29,4 & 24,6 & 23,7 & 37,9 & 19,6 & 3,7 \\
\hline Tocantins & 44,9 & 33,6 & 19,4 & 16,9 & 62,5 & 49,8 & 13,0 \\
\hline Maranhão & 76,6 & 49,9 & 29,0 & 23,5 & 69,3 & 52,9 & 19,0 \\
\hline Piauí & 65,0 & 36,4 & 23,4 & 20,4 & 68,6 & 44,1 & 13,1 \\
\hline Ceará & 79,5 & 38,1 & 19,7 & 15,8 & 80,1 & 58,5 & 19,7 \\
\hline Rio Grande do Norte & 75,7 & 44,8 & 20,6 & 16,1 & 78,7 & 64,0 & 21,6 \\
\hline Paraíba & 81,9 & 48,6 & 22,9 & 18,0 & 78,1 & 63,0 & 21,4 \\
\hline Pernambuco & 77,0 & 48,8 & 18,5 & 14,0 & 81,8 & 71,3 & 24,4 \\
\hline Alagoas & 102,2 & 63,7 & 30,2 & 22,4 & 78,1 & 64,9 & 26,0 \\
\hline Sergipe & 65,5 & 43,1 & 22,6 & 17,9 & 72,6 & 58,4 & 20,5 \\
\hline Bahia & 66,0 & 41,3 & 23,1 & 19,0 & 71,3 & 54,2 & 18,1 \\
\hline Minas Gerais & 39,0 & 25,6 & 14,6 & 12,0 & 69,3 & 53,3 & 18,2 \\
\hline Espirito Santo & 33,2 & 23,5 & 12,0 & 9,6 & 71,0 & 58,9 & 19,5 \\
\hline Rio de Janeiro & 32,3 & 19,8 & 14,1 & 12,3 & 62,0 & 38,0 & 12,6 \\
\hline São Paulo & 30,8 & 17,3 & 12,0 & 10,5 & 65,9 & 39,3 & 12,4 \\
\hline Paraná & 35,1 & 18,9 & 12,1 & 10,1 & 71,1 & 46,5 & 15,9 \\
\hline Santa Catarina & 33,6 & 15,9 & 11,2 & 9,8 & 70,8 & 38,2 & 12,5 \\
\hline Rio Grande do Sul & 26,2 & 15,3 & 11,4 & 10,2 & 61,3 & 33,5 & 10,8 \\
\hline Mato Grosso do Sul & 32,3 & 24,2 & 17,0 & 14,9 & 53,8 & 38,3 & 12,3 \\
\hline Mato Grosso & 37,5 & 25,1 & 19,5 & 17,7 & 52,8 & 29,3 & 9,3 \\
\hline Goiás & 35,1 & 23,2 & 17,7 & 15,8 & 55,0 & 32,0 & 10,9 \\
\hline Distrito Federal & 28,9 & 15,2 & 12,0 & 11,0 & 62,0 & 27,5 & 8,3 \\
\hline
\end{tabular}

Fonte: IBGE, Censo Demográfico 1991/2010 e Projeção da População das Unidades da Federação por Sexo e Idade 2000-2030.

As estimativas encontradas para a mortalidade infantil corroboram resultados já analisados em outros estudos, divulgados anteriormente e que apontavam a associação existente entre esse indicador e o status socioeconômico da mulher, no sentido de que crianças menores de 1 ano de idade, cujas mães estão inseridas nos estratos sociais de menor instrução, ainda exibem as taxas mais elevadas, enquanto os grupos de crianças de mães de estratos sociais intermediários e os de maior instrução, em escala ordenada, apresentam menores valores (SIMÕES, 1997, 2002, 2016). 


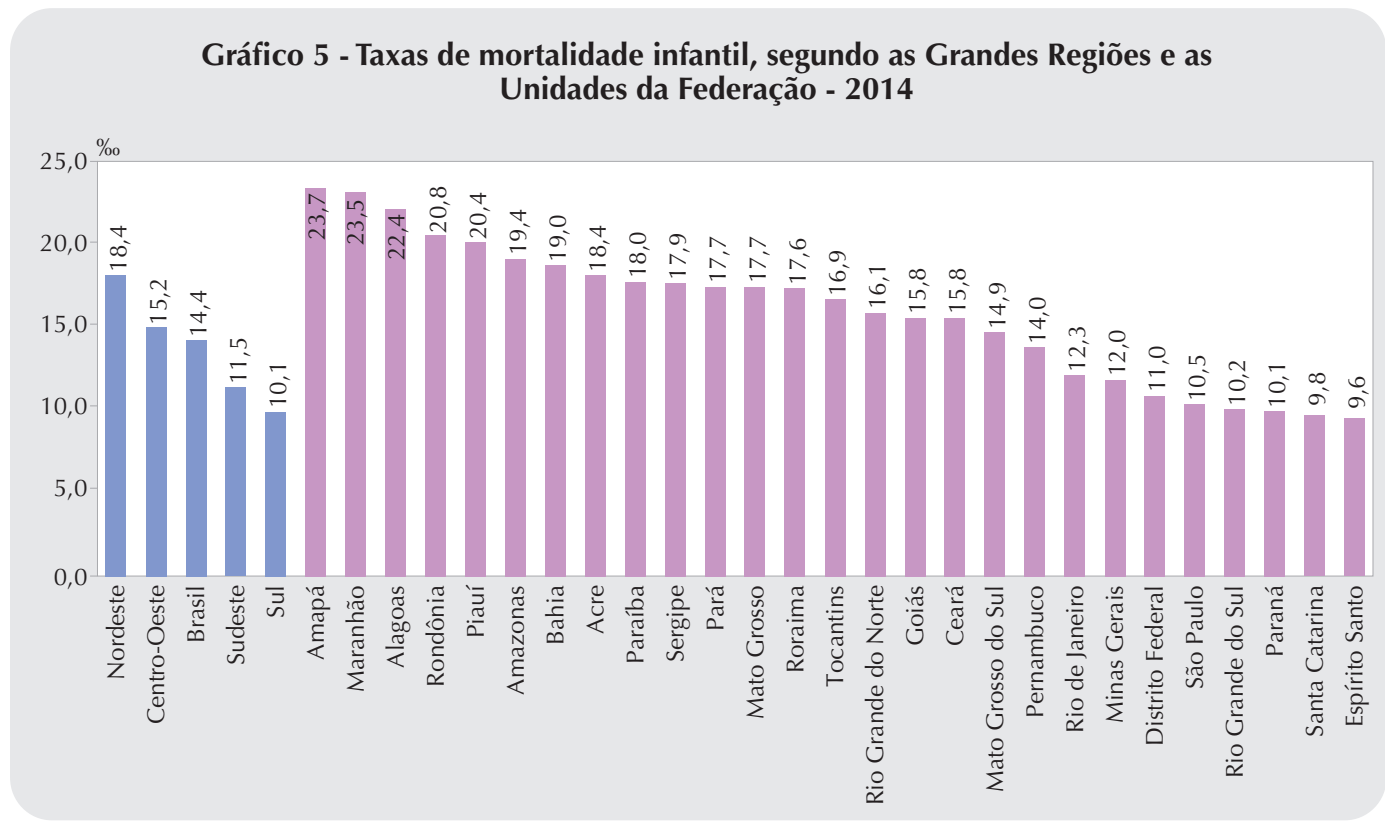

Fonte: IBGE, Projeção da População das Unidades da Federação por Sexo e Idade 2000-2030.

Em síntese, o Brasil, apesar das importantes reduções observadas no indicador, no decorrer dos últimos 25 anos, ainda exibe heterogeneidades internas, não só do ponto de vista geográfico, mas igualmente quando se leva em consideração a inserção das crianças nos distintos estratos sociais. Se, por um lado, no caso das Regiões Norte e Nordeste, apesar do importante declínio observado na mortalidade infantil, vale salientar, conforme já exposto, que, em alguns estados dessas regiões, seus valores permanecem relativamente elevados quando comparados aos das regiões do Centro-Sul do País. Ou seja, a insuficiência de oferta de importantes serviços que foram responsáveis pela queda da mortalidade infantil nas áreas mais dinâmicas do País e a sua estrutura econômica mais rígida, ao excluir contingentes significativos da população dos benefícios sociais, continua sendo um obstáculo que deve ser removido, para que se intensifique, ainda mais, o processo de queda que vem se observando na mortalidade infantil nessas áreas.

Saliente-se que, mesmo na maioria das regiões do Centro-Sul, onde se verificam valores relativamente baixos da mortalidade infantil, os índices apresentados são elevados quando comparados com os encontrados em países mais desenvolvidos e/ou naqueles que apresentam menores desigualdades sociais (abaixo de 5\%), a exemplo do Japão, Canadá, França e Portugal, dentre outros.

Por fim, enfatize-se que o nível médio da mortalidade infantil brasileira, estimado para o ano 2014, de 14,4 óbitos infantis por 1000 nascidos vivos, está fortemente influenciado pelos níveis ainda relativamente elevados que predominam em algumas das Unidades da Federação das Regiões Norte e Nordeste. Nesse sentido, para suavizar esses efeitos, num curto prazo de tempo, as políticas sociais, econômicas e de saúde deverão ser, em grande medida, fortalecidas, reorientadas e monitoradas, concentrando-se esforços nessas regiões. 


\section{Histórico do processo de evolução das taxas de fecundidade total ${ }^{6}$}

Um dos componentes mais importantes da dinâmica demográfica é a fecundidade, que afeta de maneira profunda as estruturas etárias das populações. Níveis elevados das taxas de fecundidade total estão associados a estruturas etárias muito jovens e baixa proporção de pessoas idosas.

Até meados da década de 1960, apesar do processo de urbanização e industrialização que vinha ocorrendo a partir de 1930, os níveis de fecundidade mantiveram-se elevados e estáveis, ainda que os diferenciais regionais e sociais fossem crescentes. Nos Estados do Rio de Janeiro e de São Paulo, e em parte da Região Sul, desde 1940, a fecundidade já vinha passando por um processo de declínio, com patamares ligeiramente mais baixos ano a ano, tendência esta que antecipava a diminuição acelerada, verificada, posteriormente, em todo o País.

A partir de 1960, constata-se a intensificação, cada vez mais generalizada e rápida, do declínio da fecundidade, que se consolida durante as décadas de 1970 e 1980, em todas as regiões brasileiras, inclusive nas áreas rurais e em grupos sociais mais pobres. A literatura especializada comumente contempla uma série de causas e motivações com vistas a explicar a súbita mudança no comportamento reprodutivo da população brasileira. Entre elas, vale destacar fatores econômicos, sociais, político-institucionais e as chamadas variáveis intermediárias, inibidoras da fecundidade, como determinadas características de natureza demográfica e o conhecimento e uso de métodos anticoncepcionais.

Os primeiros fatores assinalados, de natureza estrutural, respondem pela determinação, em última instância, dos padrões de dinâmica demográfica. Isto, necessariamente, porque o significado histórico das relações entre a dinâmica populacional e a formação social concreta somente pode ser apreendido quando se situa a variável população em sua interação com as transformações e a dinâmica específica das relações sociais e da organização produtiva.

É importante chamar a atenção para o fato de que, a partir da década de 1960, se inicia, no País, a difusão dos métodos anticonceptivos, particularmente nas regiões do Centro-Sul. Até essa década, a taxa de fecundidade total, que era levemente superior a seis filhos por mulher, declina, em 1970, para 5,8 filhos, em decorrência da redução mais forte observada na Região Sudeste (Tabela 9 e Gráfico 6).

Segundo a publicação Nupcialidade e fecundidade: resultados da amostra do Censo Demográfico 2000 (2003, p. 55):

\footnotetext{
6 Conceitualmente, a taxa de fecundidade total representa o número médio de filhos nascidos vivos, tidos por uma mulher ao final de seu período reprodutivo, na população residente, em determinado espaço geográfico. Esse indicador é o principal determinante da dinâmica demográfica, não sendo afetado pela estrutura etária da população. Expressa a situação reprodutiva de uma mulher pertencente a uma coorte hipotética, sujeita às taxas específicas de fecundidade por idade, observadas na população em estudo, supondo-se a ausência de mortalidade nesta coorte.
} 
Por se tratar da região mais urbanizada do País, proporcionando um maior acesso aos meios existentes para evitar uma gravidez não desejada, e dispor de um parque industrial e de uma rede de comércio e serviços, impulsionadores da economia nacional, que absorvia um número cada vez maior de mão de obra feminina, a Região Sudeste do Brasil foi a primeira a experimentar a maior redução no nível da fecundidade: quase 2 filhos de 1960 a 1970.

Já, nas Regiões Sul e Centro-Oeste, o início da transição da fecundidade se processa a partir dos primeiros anos da década de 1970, enquanto, nas Regiões Norte e Nordeste, este fato se verifica a partir do início da década de 1980, em decorrência da prática de uma política não "oficializada" de esterilização, uma vez que a grande maioria das mulheres que "optavam" por este procedimento, realizava-o na rede pública hospitalar.

Tabela 9 - Taxas de Fecundidade Total, segundo as Grandes Regiões - 1940/2014

\begin{tabular}{l|c|c|c|c|c|c|c|c|c}
\hline \multirow{2}{*}{ Grandes Regiões } & \multicolumn{7}{c}{ Taxas de Fecundidade Total (TFT) } \\
\cline { 2 - 11 } & 1940 & 1950 & 1960 & 1970 & 1980 & 1991 & 2000 & 2010 & 2014 \\
\hline \multirow{2}{*}{ Brasil } & $\mathbf{6 , 1 6}$ & $\mathbf{6 , 2 1}$ & $\mathbf{6 , 2 8}$ & $\mathbf{5 , 7 6}$ & $\mathbf{4 , 3 5}$ & $\mathbf{2 , 8 5}$ & $\mathbf{2 , 3 9}$ & $\mathbf{1 , 8 7}$ & $\mathbf{1 , 5 7}$ \\
Norte & 7,17 & 7,97 & 8,56 & 8,15 & 6,45 & 4,15 & 3,18 & 2,40 & 2,16 \\
Nordeste & 7,15 & 7,50 & 7,39 & 7,53 & 6,13 & 3,75 & 2,72 & 2,02 & 1,85 \\
Sudeste & 5,69 & 5,45 & 6,34 & 4,56 & 3,45 & 2,36 & 2,11 & 1,70 & 1,61 \\
Sul & 5,65 & 5,70 & 5,89 & 5,42 & 3,63 & 2,50 & 2,17 & 1,70 & 1,60 \\
Centro-Oeste & 6,36 & 6,86 & 6,74 & 6,42 & 4,51 & 2,69 & 2,25 & 1,83 & 1,72 \\
\hline
\end{tabular}

Fonte: IBGE, Censo Demográfico 1940/2010 e Projeção da População das Unidades da Federação por Sexo e Idade 2000-2030.

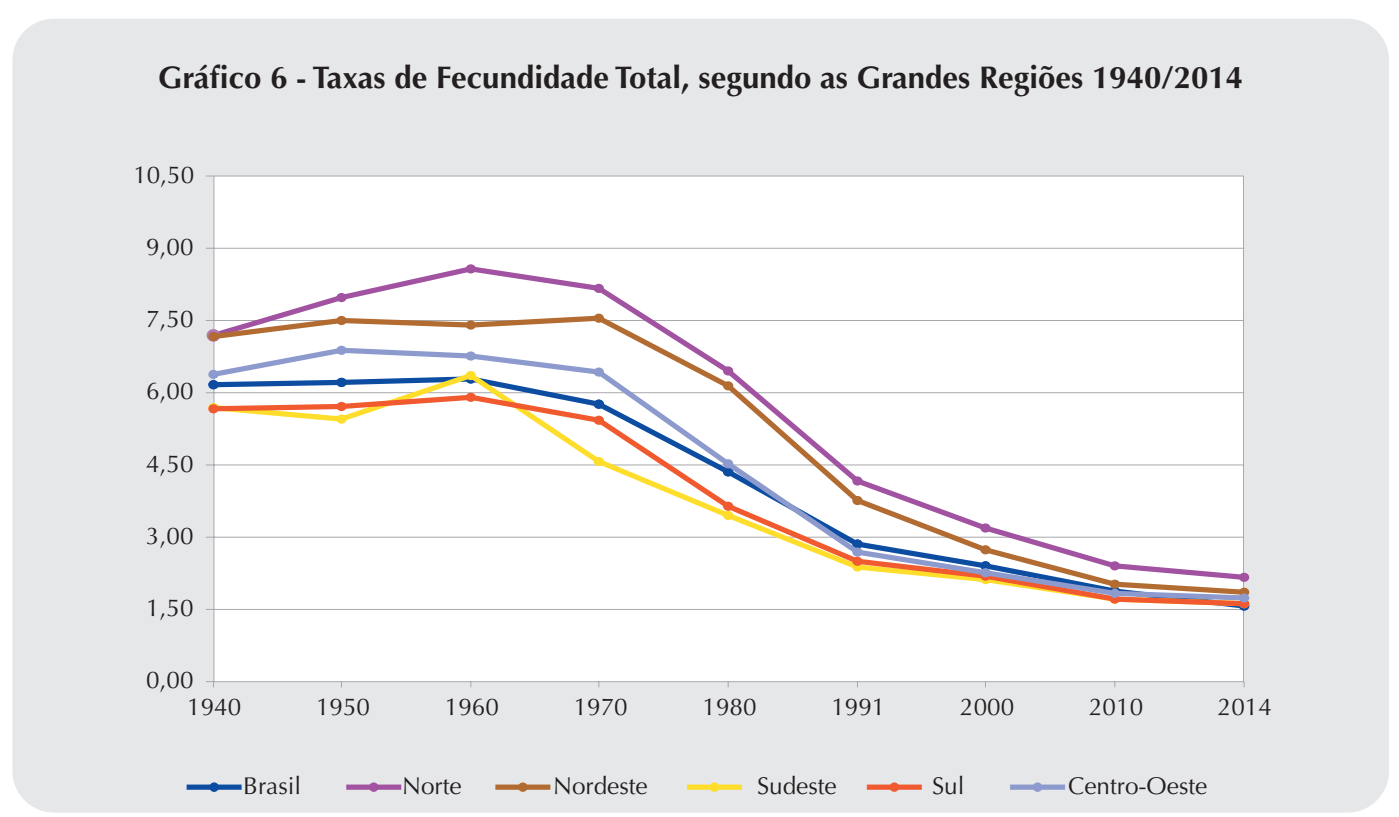

Fonte: IBGE, Censo Demográfico 1940/2010 e Projeção da População das Unidades da Federação por Sexo e Idade 2000-2030. 
Durante a década de 1980, manteve-se o ritmo de declínio, chegando, em 2000, à estimativa da ordem de 2,39 filhos por mulher e de 1,87 filho, em 2010. De acordo com as Projeções da População por Sexo e Idade, divulgadas pelo IBGE em 2013, a estimativa cai para 1,57 filho, indicativo de que a fecundidade no País já se encontra bem inferior ao nível de reposição (2,1 filhos por mulher). Trata-se de um rápido e espetacular declínio, num espaço de tempo bastante reduzido (34 anos), quando comparado à experiência vivenciada pelos países desenvolvidos, cujo processo teve uma duração superior a um século para atingir patamares similares.

Considerando as diferenças regionais, verifica-se que as Regiões Norte e Nordeste, justamente as mais ruralizadas do País, lideravam o ranking da fecundidade mais elevada. Em 1970, essas duas regiões apresentavam taxas de fecundidade superiores a sete filhos por mulher, enquanto a Região Sudeste já apresentava valores bem abaixo (4,6 filhos por mulher). O processo de declínio da fecundidade, sobretudo a partir dos anos 1980, generalizou-se por todas as regiões e grupos sociais, de tal forma que, em 2010, mesmo as regiões que antes tinham fecundidade elevada, com exceção da Região Norte $(2,40)$ já apresentavam taxas reduzidas, inferiores aos níveis de reposição $(2,02)$, conforme é exibido na Tabela 9. Vale salientar que, em 2000, as taxas de fecundidade total estimadas para as Regiões Sudeste e Sul, cujos valores estavam em torno de 2,1 filhos por mulher, já podiam ser consideradas como tendo atingido níveis de reposição. As demais regiões também continuaram mantendo a tendência de queda, a ponto de que, para o ano de 2014, todas as regiões já apresentam valores inferiores a 2,1 filhos por mulher, com exceção da Região Norte, que estaria no limite.

Os resultados confirmam a associação entre posição socioeconômica da população e níveis de fecundidade, no sentido de que os grupos menos instruídos ainda apresentam taxas de fecundidade mais elevadas, enquanto os grupos intermediários e os mais instruídos, em escala ordenada, detêm menores valores. Todavia, cabe esclarecer que as diferenças entre as taxas de fecundidade total do primeiro e último estrato educacional vêm se reduzindo de maneira acentuada nas últimas décadas (Tabela 10), independentemente da região de residência.

Tabela 10 - Diferença entre o número de filhos de mulheres com até 3 anos de instrução e de mulheres com 8 anos e mais de instrução, por Grandes Regiões -1970/2014

\begin{tabular}{|c|c|c|c|c|c|c|}
\hline \multirow[t]{2}{*}{ Ano } & \multicolumn{6}{|c|}{$\begin{array}{l}\text { Diferença entre o número de filhos de mulheres com até } 3 \text { anos de instrução e } \\
\text { de mulheres com } 8 \text { anos e mais de instrução }\end{array}$} \\
\hline & Brasil & Norte & Nordeste & Sudeste & Sul & Centro Oeste \\
\hline 1970 & 4,54 & 5,51 & 5,28 & 4,03 & 3,98 & 4,56 \\
\hline 1980 & 4,16 & 4,34 & 3,94 & 2,79 & 2,67 & 2,88 \\
\hline 1991 & 2,15 & 3,20 & 2,77 & 1,44 & 1,70 & 1,61 \\
\hline 2000 & 1,81 & 2,76 & 2,08 & 1,35 & 1,53 & 1,36 \\
\hline 2010 & 1,56 & 2,18 & 1,58 & 1,12 & 1,31 & 1,15 \\
\hline 2014 & 1,31 & 1,96 & 1,25 & 1,06 & 1,23 & 1,08 \\
\hline
\end{tabular}

Fontes: 1. IBGE, Censo Demográfico 1970/2010 e Projeção da População das Unidades da Federação por Sexo e Idade 2000-2030. 2. Simões, C. C. da S. Relações entre as alterações históricas na dinâmica demográfica brasileira, políticas públicas e impactos futuros decorrentes do processo de envelhecimento da população. Rio de Janeiro: IBGE, Departamento de Pesquisas, 2016. No prelo. 
No Brasil, o diferencial que era, em 1970, de 4,5 filhos por mulher, declina para 1,3 filho, em 2014, relacionado, de acordo com o estudo desenvolvido por Simões (2016), com a acentuada queda da taxa de fecundidade total estimada para mulheres com até 3 anos de escolaridade, que passa de 7,2 filhos para 2,5 filhos, durante o período analisado (Gráfico 7).

Importante destacar que, a partir de 1980, as mulheres mais instruídas começaram a ter taxas de fecundidade total abaixo do nível de reposição, sendo que, em 2010, de acordo com o estudo anteriormente citado, esse valor situava-se em 1,4 filho, reduzindo-se, ainda mais, em 2014 (1,2 filho), indicativo de um maior controle da reprodução por parte destes segmentos populacionais mais instruídos. Também dentro da perspectiva regional, podem-se constatar mudanças nos padrões reprodutivos da mulher brasileira.

Ressalte-se que os decréscimos nacional e regional da fecundidade vêm ocorrendo em todos os estratos sociais. Vale chamar a atenção para o fato de que o nível de instrução da mãe tem sido uma das principais variáveis socioeconômicas a receber atenção especial nos estudos, tanto de mortalidade como de fecundidade, por ser um fator determinante na transformação de conduta da mulher frente à reprodução, além de ser proxy de condição socioeconômica. Além disso, a educação influencia a conduta da mãe desde a gravidez até a criação e o desenvolvimento dos filhos. A adoção de práticas mais sadias e a maior percepção quanto ao cuidado e o trato de higiene e de saúde dos filhos, e um maior poder de decisão da mãe mais instruída dentro do domicílio, sobretudo em relação à proteção das crianças, estariam por detrás do papel da educação da mãe, na melhoria, não só das condições de sobrevivência das crianças, mas também na redução dos níveis de fecundidade.

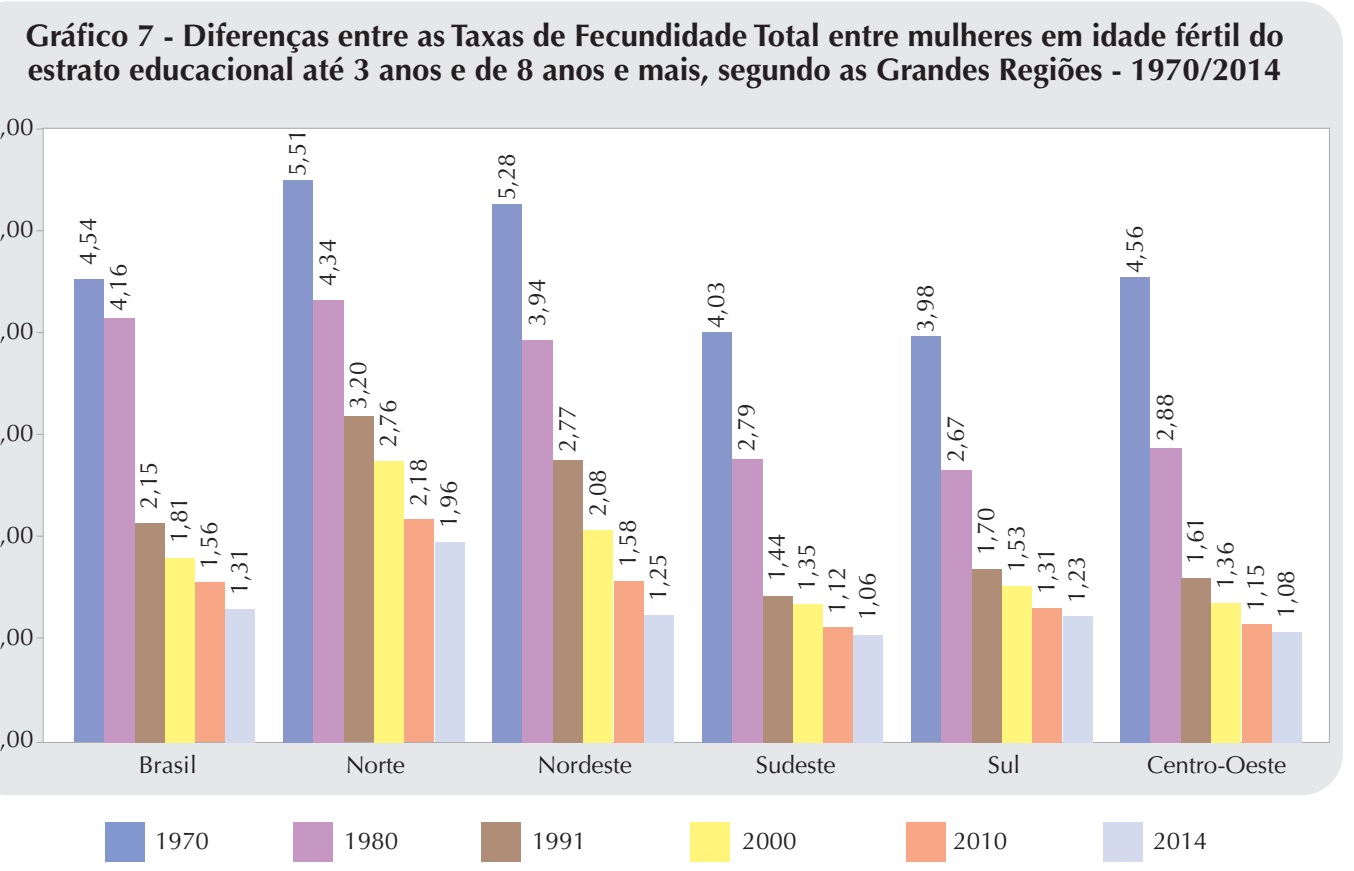

Fonte: IBGE, Censo Demográfico 1970/2010 e Projeção da População das Unidades da Federação por Sexo e Idade $2000-2030$. 
Em síntese, em decorrência dos resultados apresentados, pode-se inferir que o avanço na escolaridade por parte das mulheres, observado no decorrer das últimas décadas, tem sido um importante condicionante que operou e vem agindo no sentido da redução do número de filhos, numa perspectiva de um melhor posicionamento na estrutura da sociedade, uma vez que o custo de uma família numerosa é cada vez mais elevado.

Por outro lado, independentemente da melhoria da escolaridade, como fator de redução da fecundidade, o que vem se notando é que, mesmo nos segmentos menos instruídos, os níveis de fecundidade também se reduziram intensamente, indicativo de que expressivas parcelas da população pobre também vêm, no decorrer das últimas décadas, incorporando padrões de comportamento reprodutivo típicos de segmentos da classe média moderna. Aspectos culturais, relativos às mudanças na organização familiar e no papel desempenhado pelas mulheres, igualmente, apresentam um peso na consolidação de um comportamento reprodutivo em níveis reduzidos de fecundidade.

Um resultado relevante da mudança nos níveis de fecundidade, com a consequente redução do número de nascimentos, refere-se a seus efeitos sobre as estruturas etárias da população ${ }^{7}$ e seus impactos que já vêm sendo vivenciados pela sociedade brasileira na formulação de novas políticas públicas sociais, objeto de análise da próxima seção.

\section{Os efeitos das alterações da dinâmica demográfica brasileira sobre as estruturas etárias e os impactos nas políticas públicas}

No decorrer do capítulo, foram apresentadas evidências sobre as profundas mudanças na dinâmica demográfica brasileira, particularmente no que se refere aos aspectos relacionados com a fecundidade. Constatou-se que o processo de transição da fecundidade, apesar de ter principiado em momentos diferentes do tempo, foi resultante dos distintos aspectos estruturais das transformações sociais apresentadas entre as regiões brasileiras. Essas alterações, por terem tido início retardado nas Regiões Norte e Nordeste, em relação às do Centro-Sul, fizeram com que o ritmo de queda da fecundidade obedecesse a um movimento com temporalidade própria.

Por exemplo, mesmo apresentando taxas de fecundidade mais altas, o declínio relativo naquelas regiões durante a década de 1970 foi inferior ao das regiões mais desenvolvidas. Contudo, a partir dos anos 1980, o declínio da fecundidade das Regiões Nordeste e Norte começa a ser proporcionalmente maior do que o das Regiões Sudeste e Sul, evidenciando a tendência generalizadora do processo de transição de fecundidade pelo conjunto das regiões do País, alcançando as áreas e os grupos sociais, em que a fecundidade era, até então, mais elevada.

\footnotetext{
7 Na elaboração da pirâmide, foram utilizadas as informações dos Censos Demográficos e as Projeções da População do Brasil por Sexo e Idade até o ano 2050, realizadas pelo IBGE. Chama-se a atenção para a convergência das estruturas etárias implícitas do Censo Demográfico 2010 e as derivadas das Projeções para esse mesmo ano.
} 
Exibir as implicações das mudanças nos padrões demográficos, particularmente nas questões relacionadas com o comportamento reprodutivo, as estruturas etárias e a redefinição de políticas públicas direcionadas a grupos sociais específicos, é o foco dos tópicos seguintes.

\section{Os impactos do novo processo demográfico nas alterações das estruturas etárias da população brasileira}

Uma consequência relevante das alterações verificadas nos padrões demográficos no Brasil, sobretudo nos níveis de fecundidade, que resultou na redução do número de nascimentos, refere-se a seus efeitos sobre as estruturas de distribuição etária da população.

Se, até o final dos anos 1970, a estrutura etária da população brasileira era predominantemente jovem, em decorrência dos níveis então elevados da fecundidade, a partir da década de 1980, inicia-se um estreitamento da base da pirâmide, com reduções significativas do número de crianças e adolescentes no total da população. Essa tendência reflete claramente o processo de declínio da fecundidade, quando se consideram as estimativas do indicador, levando em conta as informações do Censo Demográfico 1980, que se intensifica no decorrer das décadas seguintes. Quanto à diminuição relativa do número de crianças, acrescenta-se, inicialmente, um aumento em termos absolutos, em decorrência da inércia demográfica e uma posterior diminuição a partir do ano 2000 (Gráfico 8).

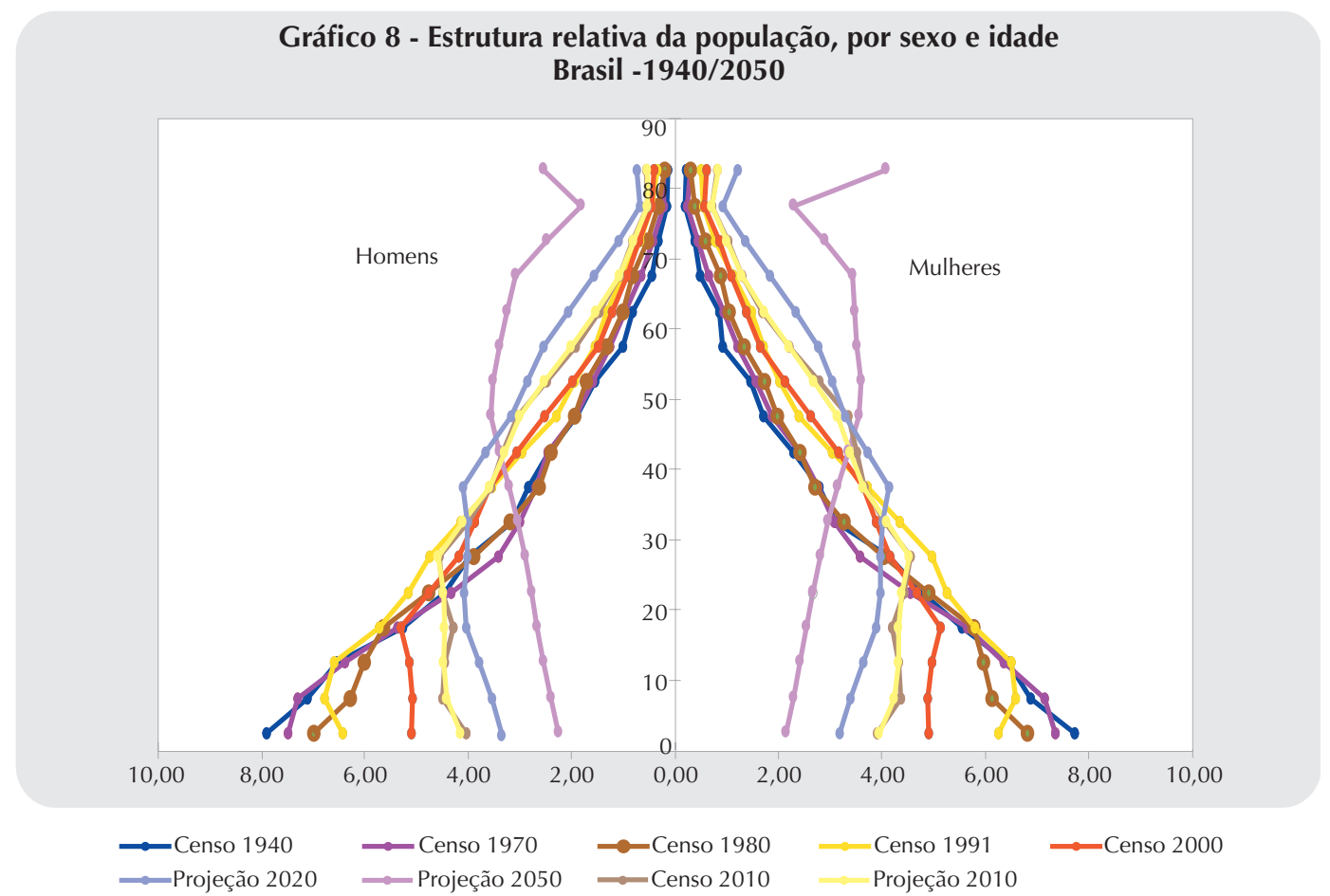

Fonte: IBGE, Censo Demográfico 1940/2010 e Projeção da População do Brasil por Sexo e Idade 2000-2060. 
As estruturas das pirâmides ainda revelam o peso de coortes etárias provenientes de nascimentos de períodos em que a fecundidade ainda era elevada. Desse modo, a partir de 1991, percebe-se nitidamente o salto no crescimento, em termos relativos e absolutos, da população em idade ativa (15 a 59 anos), ou seja, os chamados jovens e adultos. Em termos absolutos (Tabela 11), o total da população deste grupo etário pulou de 85,1 milhões para 126,0 milhões, em 2010. Ou seja, um incremento de 22,0 milhões, durante 19 anos, numa fase que coincide com mudanças cíclicas na economia e reestruturação do mercado de trabalho. Nesse período, o crescimento do número de idosos ${ }^{8}$ já se faz notar, de forma mais nítida, com um incremento absoluto de 8,9 milhões, enquanto, entre as crianças e adolescentes de 0 a 14 anos de idade, o valor foi negativo (-1,1 milhão).

Tabela 11 - População residente, total e proporção, por grupos de idade - Brasil - 1940/2050

\begin{tabular}{|c|c|c|c|c|c|c|c|}
\hline \multirow{3}{*}{ Ano } & \multicolumn{7}{|c|}{ População residente } \\
\hline & \multicolumn{4}{|c|}{ Total } & \multicolumn{3}{|c|}{ Proporção (\%) } \\
\hline & Total & $\begin{array}{c}\text { De } 0 \text { a } \\
14 \text { anos }\end{array}$ & $\begin{array}{l}\text { De } 15 \text { a } \\
59 \text { anos }\end{array}$ & $\begin{array}{c}\text { De } 60 \text { anos } \\
\text { e mais }\end{array}$ & $\begin{array}{c}\text { De } 0 \text { a } \\
14 \text { anos }\end{array}$ & $\begin{array}{l}\text { De } 15 \text { a } \\
59 \text { anos }\end{array}$ & $\begin{array}{l}\text { De } 60 \text { anos } \\
\text { e mais }\end{array}$ \\
\hline 1940 & 41132884 & 17523641 & 21942119 & 1667124 & 42,60 & 53,34 & 4,05 \\
\hline 1950 & 51784603 & 21670246 & 27916906 & 2197451 & 41,85 & 53,91 & 4,24 \\
\hline 1960 & 69957865 & 29854870 & 36790575 & 3312420 & 42,68 & 52,59 & 4,73 \\
\hline 1970 & 92955059 & 39130433 & 49108418 & 4716208 & 42,10 & 52,83 & 5,07 \\
\hline 1980 & 118874665 & 45460763 & 66197885 & 7216017 & 38,24 & 55,69 & 6,07 \\
\hline 1991 & 146825475 & 50988432 & 85114338 & 10722705 & 34,73 & 57,97 & 7,30 \\
\hline 2000 & 173448346 & 52107064 & 107105551 & 14235731 & 30,04 & 61,75 & 8,21 \\
\hline 2010 & 195497797 & 49934121 & 125961822 & 19601854 & 25,54 & 64,43 & 10,03 \\
\hline 2020 & 212077375 & 44315024 & 138471689 & 29290662 & 20,90 & 65,29 & 13,81 \\
\hline 2030 & 223126917 & 39256945 & 142328209 & 41541763 & 17,59 & 63,79 & 18,62 \\
\hline 2040 & 228153204 & 35441110 & 138507200 & 54204894 & 15,53 & 60,71 & 23,76 \\
\hline 2050 & 226347688 & 31849189 & 128040929 & 66457570 & 14,07 & 56,57 & 29,36 \\
\hline
\end{tabular}

Fonte: IBGE, Censo Demográfico 1940/2010 e Projeção da População do Brasil por Sexo e Idade 2000-2060.

O aumento contínuo do grupo populacional que compõe a cognominada terceira idade é uma realidade, que já dá para ser percebida no cotidiano da sociedade brasileira. Só para reforçar essa questão, tendo como base as informações disponíveis da Tabela 11, observa-se que, entre 2010 e 2050, a previsão é que o grupo populacional de 60 anos e mais de idade triplique em termos absolutos, passando de 19,6 milhões para 66,5 milhões. Estas transformações nas estruturas etárias já começam a afetar a configuração das pirâmides etárias (Gráfico 8), com diminuições sucessivas de contingentes populacionais na sua base, em paralelo a aumentos contínuos nas idades posteriores, até atingir a forma de uma estrutura piramidal mais estável.

\footnotetext{
8 A definição de idoso como pessoa de 60 anos ou mais de idade é estabelecida na legislação brasileira, por meio da Lei n. 8.842, de 4 de janeiro de 1994, regulamentada pelo Decreto n. 1.948, de 3 de julho de 1996, que dispõe sobre a política nacional do idoso (BRASIL, 1994, 1996). A Organização Mundial da Saúde - OMS (World Health Organization - WHO) também vem adotando esse critério para esse grupo específico.
} 
Por outro lado, observa-se, em âmbito nacional, que a participação do grupo de crianças e adolescentes de 0 a 14 anos de idade, apesar do aumento observado, em valores absolutos, em termos relativos, manteve-se estável $(42,0 \%)$ até 1970 , quando se inicia um processo de declínio, atingindo, em 2010, uma proporção de 25,5\%. Essa redução se contrapõe não só aos grupos populacionais em idade de trabalhar ( 15 a 59 anos), mas também ao de idoso (60 anos e mais), que tiveram majoradas suas participações proporcionais na composição etária da população, conforme mostrado na Tabela 11 e no Gráfico 9. Em 2030, o número de idosos já superará o de crianças e adolescentes em cerca de 2,28 milhões, diferença que tenderá a aumentar para 34,6 milhões, em 2050 (66,5 milhões contra 31,8 milhões, respectivamente). Nesse ano, os idosos já representarão $29,4 \%$ contra $14,1 \%$ de crianças e adolescentes no total da população.

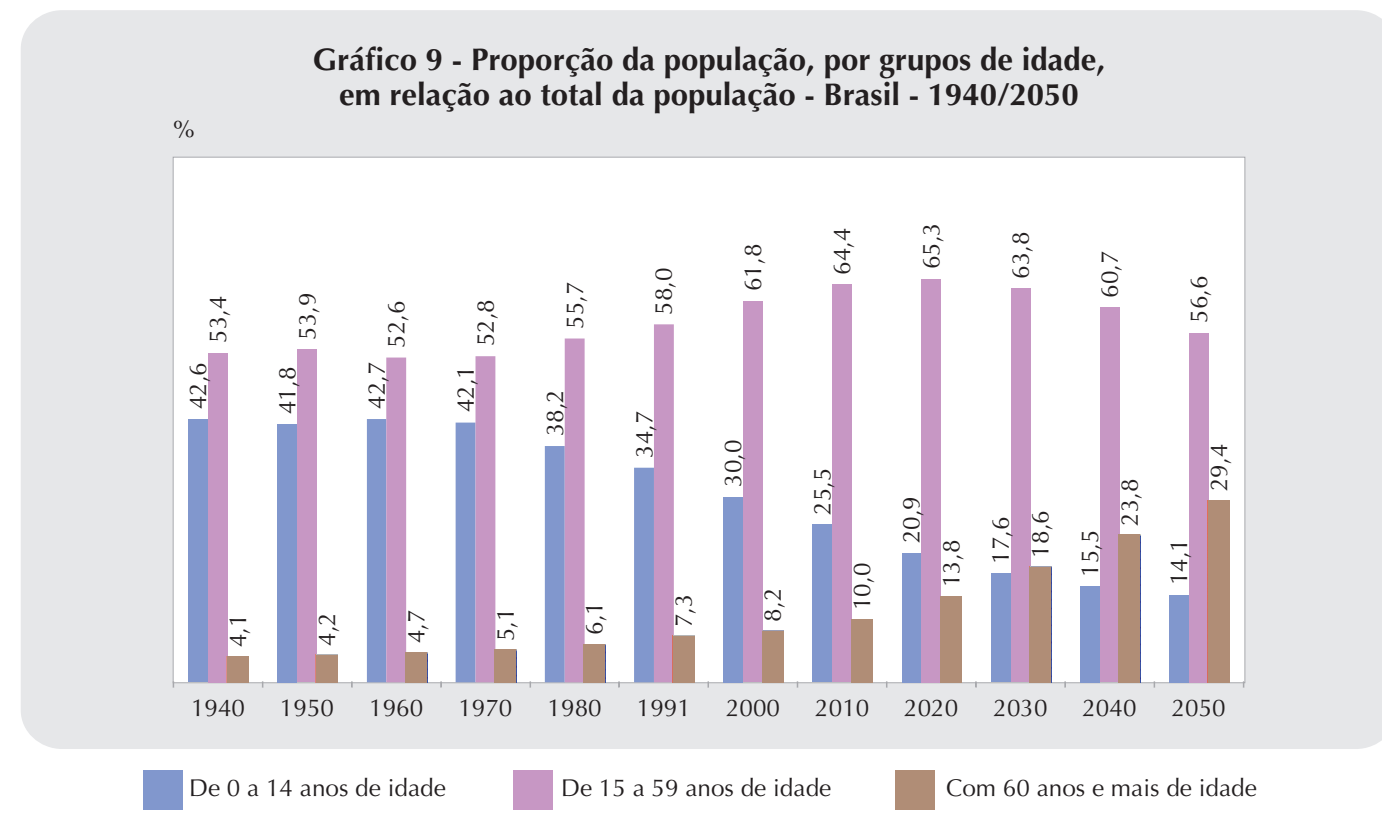

Fonte: IBGE, Censo Demográfico 1940/2010 e Projeção da População do Brasil por Sexo e Idade 2000-2060.

Uma visualização mais clara das mudanças desses grupos populacionais específicos é exibida no Gráfico 10, durante o período de 1940 a 2050. Até 2030, as Projeções da População por Sexo e Idade apontam para uma igualdade no número de crianças e adolescentes de 0 a 14 anos e de idosos de 60 anos e mais de idade. Entretanto, a tendência é que, enquanto o número de crianças e adolescentes tende a uma redução, o número de idosos, ao contrário, siga um comportamento oposto, com aumentos expressivos no decorrer das décadas seguintes. Exemplificando, de acordo com as Projeções, em 2050, a previsão é que, enquanto a tendência da proporção de crianças e adolescentes em relação ao total da população continue a se reduzir $(14,01 \%)$, a tendência da proporção de idosos de 60 anos e mais de idade é aumentar (29,36\%). Ou seja, o dobro da observada para as crianças e adolescentes de 0 a 14 anos de idade. 
Nesse sentido, a partir das informações exibidas no Gráfico 10, é importante atentar que se observa uma tendência do aumento progressivo de pessoas em idade ativa previsto para o País até 2030, consubstanciando o fenômeno denominado "bônus demográfico". A expressão vem sendo muito usada na área da demografia, procurando chamar a atenção dos gestores, na área das políticas públicas, para o momento que se está processando na dinâmica populacional brasileira, devido a seus feitos sobre a inserção de novos e velhos contingentes populacionais no mercado de trabalho, os custos da previdência social e sobre os indicadores relacionados com a violência, dentre outros. Portanto, além da busca de soluções para problemas histórico-estruturais existentes na sociedade brasileira, há que se encarar os novos obstáculos que começam a surgir decorrentes do processo de envelhecimento da população brasileira.

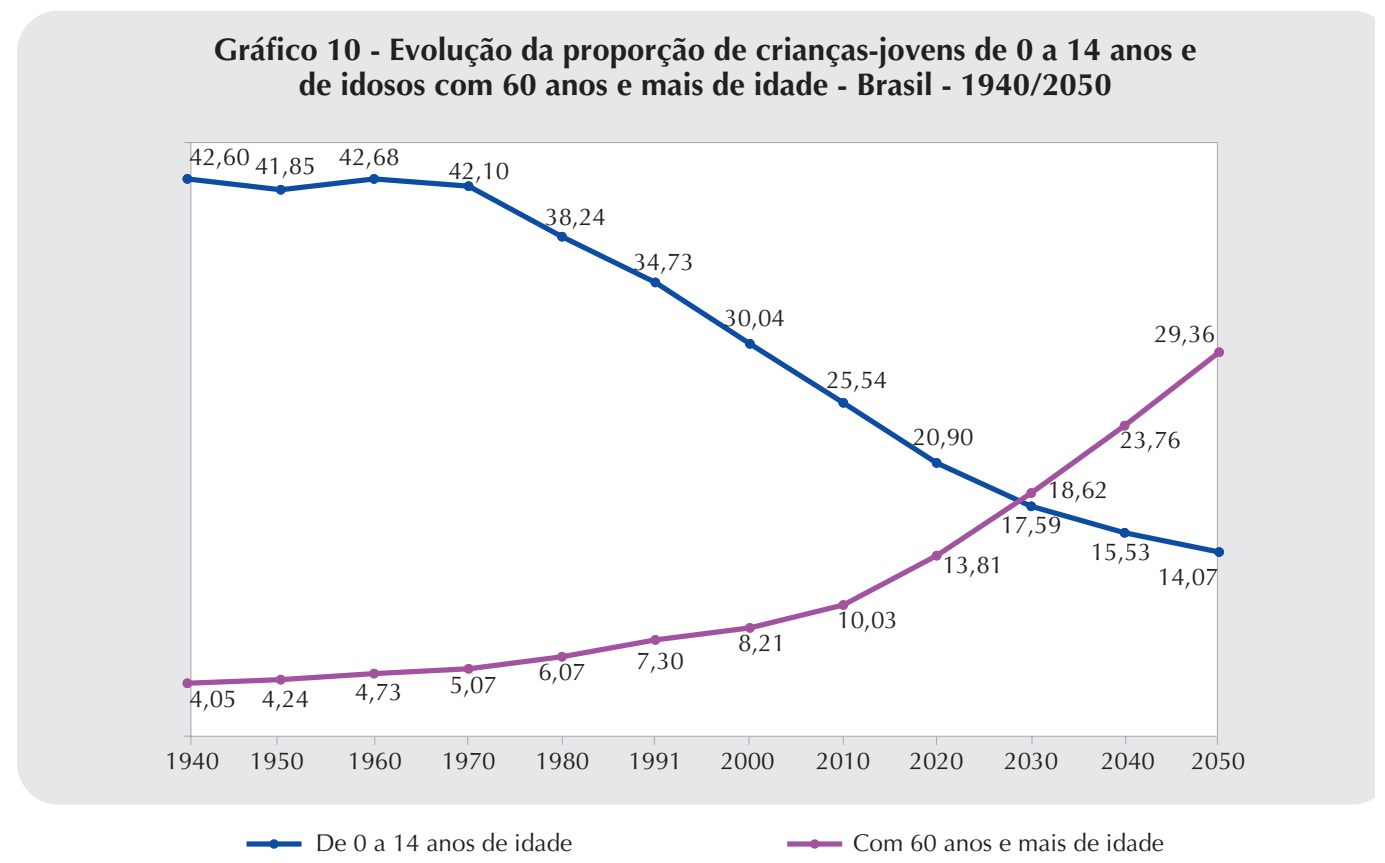

Fonte: IBGE, Censo Demográfico 1940/2010 e Projeção da População do Brasil por Sexo e Idade 2000-2060.

Cabe também destacar que as mudanças no perfil demográfico brasileiro têm sido intensivamente investigadas e retratadas nas pesquisas do IBGE, além de amplamente discutidas em seminários e congressos de especialistas em estudos de população. Ou seja, a discussão da nova realidade demográfica brasileira é cada vez mais urgente, no sentido destas questões serem levadas em consideração no planejamento e reformulação das políticas sociais, econômicas e de saúde. 
Sem dúvida, o processo de envelhecimento da população que se está vivenciando deve ser encarado, não só como um dos maiores triunfos do País, mas também como um desafio, uma vez que vem originando aumento das demandas socioeconômicas e, sobretudo, na área de saúde.

É oportuno chamar a atenção para o fato de que o impacto dos efeitos das alterações que vêm se verificando no padrão demográfico sobre as estruturas etárias, é extremamente relevante para a identificação das características das distintas gerações e coortes populacionais no País. Em decorrência, as gradativas mudanças que vão se produzindo, no decorrer do tempo, nas faixas etárias, se refletem na magnitude das mesmas e apontam para novas questões e demandas, principalmente, em relação aos serviços que as instâncias governamentais e a sociedade, de um modo geral, devem proporcionar aos distintos grupos de cidadãos, sejam eles crianças/adolescentes, jovens, adultos e idosos. Todavia, o que se percebe é que segmentos relevantes da sociedade brasileira concebem as pessoas que atingem a terceira idade, como ineficientes, quando na verdade, deveriam ser visualizadas como precioso recurso da estrutura da própria sociedade. Vale registrar que a Organização Mundial da Saúde - OMS (World Health Organization - WHO) defende a ideia de que os países têm obrigação de custear o envelhecimento. Nesse sentido, os governos, as organizações internacionais e a sociedade civil deveriam programar políticas e programas de "envelhecimento ativo", possibilitando, dessa forma, o melhoramento da saúde, a participação mais ativa e a segurança dos cidadãos mais envelhecidos.

Em decorrência da rapidez que vem se registrando, no País, o processo de enveIhecimento e as ponderações apresentadas, é de fundamental relevância adquirir, o mais rápido possível, consciência de que este é o momento oportuno para se planejar e atuar na concretização dessas ações.

Só para reforçar, na Tabela 12, é apresentado, para o conjunto nacional, regional e estadual, alguns subsídios que reforçam essas questões, a partir da comparação das faixas etárias da população de 0 a 14 anos e de 60 anos e mais de idade, para o ano 2010, considerando os seguintes indicadores: proporção de internações; gasto médio das internações (reais); e média de permanência (dias) na rede hospitalar. Assim, por exemplo, se se levar em consideração o indicador proporção de internações para cada grupo etário focado, observa-se que a média de internações de idosos é o triplo da observada no grupo de crianças e adolescentes até 14 anos de idade, para o conjunto do País. Ou seja, 12,5\% contra 4,1\%, respectivamente. Este é um padrão geral, mas com maior incidência nos estados das Regiões Sul e Centro-Oeste, quando o número de internações entre os idosos é mais de três vezes superior ao observado para o grupo etário de 0 a 14 anos. Cabe ressaltar, no entanto, que o Paraná apresenta a maior relação $(5,3)$, mas alguns estados que não fazem parte dessas regiões exibem também valores significativos, a exemplo de Amazonas $(5,0)$, Acre $(4,0)$ e Minas Gerais $(3,8)$.

O mesmo sucede com os indicadores gasto médio das internações (reais) e média de permanência (dias) na rede hospitalar. Para o Brasil como um todo, apesar de a proporção 
de crianças e adolescentes ser, em média, de 25,5\% contra 10,0\% da de idosos, devido à maior complexidade dos problemas relacionados com a saúde entre as pessoas de 60 e mais de idade, o gasto médio das internações (reais) atinge cifras superiores a $40 \%$, quando comparadas com o observado no grupo de crianças e adolescentes de 0 a 14 anos de idade.

Quanto ao indicador média de permanência (dias) na rede hospitalar, os valores também são mais expressivos no grupo de idosos de 60 e mais anos de idade, em todas as áreas espaciais focadas, sendo a média nacional de 7,6 dias, contra 4,8 dias no grupo de crianças e adolescentes de 0 a 14 anos de idade. Ou seja, uma diferença de 60,0\%. Na Região Sudeste, a média de dias de internação entre os idosos atinge a cifra de 9,4 dias, sendo que o grupo de idosos residentes no Rio de Janeiro apresenta os valores mais elevados, em comparação com o observado nas demais Unidades da Federação (13,6 dias). Ou seja, uma diferença de $140,0 \%$ em relação às crianças e adolescentes.

Conveniente enfatizar que essas diferenças tendem a se acentuar no transcorrer dos anos, uma vez que o processo de envelhecimento da população é um processo irreversível, conforme pode ser deduzido das Projeções da População por Sexo e Idade, realizadas pelo IBGE, que apontam para uma quantidade cada vez mais volumosa de idosos que, de acordo com as projeções, apontam para um valor estimado de 66,0 milhões, em 2050, enquanto o número de crianças e adolescentes é estimado em 31,8 milhões. Igualmente, é oportuno chamar a atenção para o fato de que estas informações espelham uma tendência oposta entre as duas faixas etárias extremas, uma vez que, em 2010, o quantitativo de crianças e adolescentes era de 49,9 milhões contra 19,6 milhões de idosos.

Tendo em vista este novo perfil demográfico, que, cada vez mais, apresenta a tendência de um crescimento contínuo e acentuado no número de idosos, a sociedade civil e, sobretudo, os órgãos públicos devem, urgentemente, tomar consciência sobre as consequências dessas transformações, no aceleramento nas despesas relacionadas com esse grupo populacional específico. Só para exemplificar, na Tabela 12, conforme já exposto, é constatado um diferencial expressivo nos indicadores gasto médio das internações (reais) e média de permanência (dias) na rede hospitalar no grupo populacional de idosos, em virtude da crescente complexidade das doenças e de novos procedimentos médicos que terão de ser implementados, implicando custos financeiros crescentes.

Além disso, apesar de importantes avanços verificados na área das políticas públicas e sociais, durante as últimas duas décadas, o Brasil ainda evidencia graves desigualdades sociorregionais, devendo-se, portanto, ao se pensar em planejamento de políticas públicas, considerar as especificidades peculiares de cada região, uma vez que as mesmas exibiram ritmos diferenciados de transição demográfica, que irão se refletir nas novas demandas. 
Tabela 12 - Estrutura relativa da população de 0 a 14 anos de idade e de 60 anos e mais de idade, idade média, proporção e gasto médio das internações e média de permanência na rede hospitalar, segundo as Grandes Regiões e as Unidades da Federação - 2010/2030

\begin{tabular}{|c|c|c|c|c|c|c|}
\hline \multirow{3}{*}{$\begin{array}{c}\text { Grandes Regiões } \\
\text { e } \\
\text { Unidades da Federação }\end{array}$} & \multicolumn{4}{|c|}{ Estrutura relativa $(\%)$} & \multirow{2}{*}{\multicolumn{2}{|c|}{$\begin{array}{l}\text { Idade média } \\
\text { (anos) }\end{array}$}} \\
\hline & \multicolumn{2}{|c|}{2010} & \multicolumn{2}{|c|}{2030} & & \\
\hline & $\begin{array}{l}\text { De } 0 \text { a } \\
14 \text { anos }\end{array}$ & $\begin{array}{c}\text { De } 60 \\
\text { anos e mais }\end{array}$ & $\begin{array}{l}\text { De } 0 \text { a } \\
14 \text { anos }\end{array}$ & $\begin{array}{c}\text { De } 60 \\
\text { anos e mais }\end{array}$ & 2010 & 2030 \\
\hline Brasil & 25,5 & 10,0 & 17,6 & 18,6 & 30,8 & 37,9 \\
\hline Norte & 32,7 & 6,0 & 21,5 & 11,8 & 26,2 & 33,2 \\
\hline Rondônia & 28,6 & 6,4 & 18,9 & 13,8 & 27,9 & 35,3 \\
\hline Acre & 35,7 & 5,7 & 23,6 & 10,6 & 25,1 & 31,7 \\
\hline Amazonas & 34,5 & 5,2 & 22,5 & 10,6 & 25,2 & 32,2 \\
\hline Roraima & 35,1 & 4,5 & 22,4 & 10,3 & 24,8 & 31,8 \\
\hline Pará & 32,5 & 6,4 & 21,4 & 12,1 & 26,4 & 33,4 \\
\hline Amapá & 36,2 & 4,4 & 22,6 & 10,1 & 24,3 & 31,7 \\
\hline Tocantins & 30,5 & 7,4 & 20,1 & 13,9 & 27,6 & 34,7 \\
\hline Nordeste & 28,4 & 9,1 & 19,2 & 16,0 & 29,1 & 36,2 \\
\hline Maranhão & 33,2 & 7,5 & 21,9 & 12,4 & 26,6 & 33,4 \\
\hline Piauí & 28,8 & 9,0 & 19,0 & 16,0 & 28,9 & 36,4 \\
\hline Ceará & 28,1 & 9,5 & 19,0 & 16,2 & 29,3 & 36,3 \\
\hline Rio Grande do Norte & 26,8 & 9,8 & 18,4 & 17,0 & 29,9 & 36,8 \\
\hline Paraíba & 27,0 & 10,6 & 18,9 & 16,8 & 30,2 & 36,7 \\
\hline Pernambuco & 27,4 & 9,5 & 18,8 & 16,7 & 29,8 & 36,7 \\
\hline Alagoas & 31,0 & 7,9 & 20,3 & 14,9 & 27,8 & 35,2 \\
\hline Sergipe & 28,8 & 8,0 & 19,4 & 14,8 & 28,5 & 35,5 \\
\hline Bahia & 26,9 & 9,3 & 18,5 & 17,0 & 29,7 & 37,2 \\
\hline Sudeste & 23,1 & 11,2 & 16,1 & 21,1 & 32,5 & 39,5 \\
\hline Minas Gerais & 23,7 & 11,1 & 16,3 & 20,8 & 32,0 & 39,4 \\
\hline Espírito Santo & 24,4 & 9,6 & 16,9 & 19,2 & 31,2 & 38,4 \\
\hline Rio de Janeiro & 22,5 & 12,5 & 15,99 & 22,26 & 33,5 & 40,0 \\
\hline São Paulo & 22,9 & 11,0 & 15,98 & 21,01 & 32,4 & 39,5 \\
\hline Sul & 23,0 & 11,5 & 16,19 & 21,94 & 32,6 & 39,7 \\
\hline Paraná & 24,1 & 10,7 & 16,56 & 20,91 & 31,8 & 39,2 \\
\hline Santa Catarina & 22,9 & 10,1 & 16,60 & 20,14 & 31,9 & 38,8 \\
\hline Rio Grande do Sul & 22,0 & 13,2 & 15,51 & 24,27 & 33,9 & 41,0 \\
\hline Centro-Oeste & 25,6 & 8,2 & 17,8 & 16,5 & 29,9 & 36,9 \\
\hline Mato Grosso do Sul & 26,5 & 9,0 & 18,5 & 17,4 & 30,1 & 36,9 \\
\hline Mato Grosso & 27,0 & 7,4 & 18,7 & 16,0 & 29,0 & 36,3 \\
\hline Goiás & 25,3 & 8,7 & 17,4 & 16,5 & 30,3 & 36,9 \\
\hline Distrito Federal & 24,1 & 7,5 & 17,2 & 16,4 & 29,8 & 37,3 \\
\hline
\end{tabular}


Tabela 12 - Estrutura relativa da população de 0 a 14 anos de idade e de 60 anos e mais de idade, idade média, proporção e gasto médio das internações e média de permanência na rede hospitalar, segundo as Grandes Regiões e as Unidades da Federação - 2010/2030

\begin{tabular}{|c|c|c|c|c|c|c|}
\hline \multirow{3}{*}{$\begin{array}{c}\text { Grandes Regiões } \\
\text { e } \\
\text { Unidades da Federação }\end{array}$} & \multicolumn{4}{|c|}{ Internações (1) } & \multirow{2}{*}{\multicolumn{2}{|c|}{$\begin{array}{l}\text { Média de dias internados na } \\
\text { rede hospitalar (3) }\end{array}$}} \\
\hline & \multicolumn{2}{|c|}{ Proporção (\%) } & \multicolumn{2}{|c|}{ Gasto médio (R\$) (2) } & & \\
\hline & $\begin{array}{c}\text { De } 0 \text { a } \\
14 \text { anos }\end{array}$ & $\begin{array}{c}\text { De } 60 \\
\text { anos e mais }\end{array}$ & $\begin{array}{l}\text { De } 0 \text { a } \\
14 \text { anos }\end{array}$ & $\begin{array}{c}\text { De } 60 \\
\text { anos e mais }\end{array}$ & $\begin{array}{l}\text { De } 0 \text { a } \\
14 \text { anos }\end{array}$ & $\begin{array}{c}\text { De } 60 \\
\text { anos e mais }\end{array}$ \\
\hline Brasil & 4,1 & 12,5 & 911,1 & 1245,8 & 4,8 & 7,6 \\
\hline Norte & 4,7 & 13,1 & 630,6 & 864,2 & 4,5 & 5,9 \\
\hline Rondônia & 5,1 & 15,9 & 548,8 & 650,4 & 3,5 & 5,0 \\
\hline Acre & 3,4 & 14,9 & 505,0 & 864,8 & 5,0 & 7,8 \\
\hline Amazonas & 3,0 & 15,2 & 687,0 & 1117,4 & 5,9 & 8,5 \\
\hline Roraima & 4,5 & 16,8 & 777,4 & 817,0 & 6,3 & 7,8 \\
\hline Pará & 5,6 & 12,8 & 607,7 & 818,9 & 4,2 & 5,4 \\
\hline Amapá & 2,5 & 11,8 & 658,7 & 899,9 & 6,9 & 7,6 \\
\hline Tocantins & 5,6 & 16,2 & 752,0 & 966,5 & 4,3 & 4,8 \\
\hline Nordeste & 4,3 & 11,9 & 723,9 & 958,7 & 4,5 & 6,3 \\
\hline Maranhão & 4,1 & 11,9 & 628,7 & 717,6 & 4,9 & 5,7 \\
\hline Piauí & 4,7 & 15,8 & 590,7 & 700,7 & 4,3 & 4,8 \\
\hline Ceará & 3,7 & 11,7 & 857,7 & 1051,5 & 5,0 & 6,0 \\
\hline Rio Grande do Norte & 3,4 & 10,4 & 859,6 & 1293,6 & 5,1 & 7,1 \\
\hline Paraíba & 4,6 & 12,9 & 716,0 & 1012,2 & 4,4 & 5,6 \\
\hline Pernambuco & 4,0 & 11,9 & 773,7 & 1074,8 & 4,8 & 8,3 \\
\hline Alagoas & 4,6 & 10,1 & 767,8 & 953,5 & 4,7 & 5,9 \\
\hline Sergipe & 2,6 & 7,1 & 1039,6 & 1193,3 & 5,0 & 6,6 \\
\hline Bahia & 5,0 & 12,2 & 656,0 & 889,3 & 3,9 & 6,0 \\
\hline Sudeste & 3,7 & 11,4 & 1094,9 & 1434,3 & 5,2 & 9,4 \\
\hline Minas Gerais & 3,5 & 13,3 & 1210,4 & 1374,2 & 4,7 & 7,1 \\
\hline Espírito Santo & 3,6 & 11,6 & 1107,2 & 1249,3 & 5,3 & 6,8 \\
\hline Rio de Janeiro & 3,4 & 7,9 & 766,9 & 1380,8 & 5,6 & 13,6 \\
\hline São Paulo & 3,8 & 11,9 & 1148,1 & 1495,1 & 5,4 & 9,4 \\
\hline Sul & 4,5 & 15,7 & 1146,4 & 1346,7 & 4,9 & 6,5 \\
\hline Paraná & 4,9 & 26,2 & 1038,4 & 1334,3 & 4,5 & 5,5 \\
\hline Santa Catarina & 3,8 & 15,0 & 1131,4 & 1473,5 & 4,7 & 7,2 \\
\hline Rio Grande do Sul & 4,5 & 14,4 & 1280,4 & 1300,4 & 5,4 & 7,0 \\
\hline Centro-Oeste & 4,5 & 15,2 & 892,1 & 1075,6 & 4,6 & 6,0 \\
\hline Mato Grosso do Sul & 4,5 & 15,5 & 1007,5 & 1175,7 & 4,5 & 5,8 \\
\hline Mato Grosso & 4,4 & 14,3 & 908,5 & 1032,6 & 4,3 & 5,3 \\
\hline Goiás & 4,5 & 16,4 & 794,7 & 988,2 & 4,2 & 5,5 \\
\hline Distrito Federal & 4,6 & 12,9 & 989,3 & 1297,4 & 6,2 & 10,0 \\
\hline
\end{tabular}

Fontes: IBGE, Projeção da População das Unidades da Federação por Sexo e Idade 2000-2030. 2. Internações hospitalares. In: Brasil. Ministério da Saúde. Sistema de Informações Hospitalares do SUS - SIH/SUS: arquivos dissemináveis para tabulação. Brasília, DF: Ministério da Saúde, Departamento de Informática do Sistema Único de Saúde - SUS - Datasus, [2014]. Disponível em: <http://www2.datasus.gov.br/DATASUS/index.php?area=0901>. Acesso em: mar. 2014.

(1) Refere-se às internações realizadas no Sistema Único de Saúde - SUS. (2) O gasto médio é obtido através da despesa total com internações SUS, dividido pelo número total de internações. (3) Refere-se aos dias de internação. 
Neste aspecto, variações e flutuações quanto aos valores populacionais projetados são factíveis de ocorrer em decorrência das distintas transições verificadas por cada uma das áreas consideradas.

\section{Considerações finais}

Em decorrência das análises realizadas, são claras as evidências de que o Brasil iniciou o Século XXI com uma nova configuração de padrão demográfico, decorrente das profundas transformações nos níveis e padrões de fecundidade e mortalidade verificados ao longo das últimas décadas, sobretudo, do aceleramento do declínio da fecundidade, observado a partir da década de 1970. Este processo aconteceu de forma generalizada, atingindo indistintamente todas as Grandes Regiões, Unidades da Federação e estratos sociais, a ponto de, a partir de 2000, já existirem poucas diferenças entre os valores das taxas encontradas para as regiões brasileiras, principalmente, em relação à fecundidade.

Nesse sentido, a recente configuração demográfica traz à luz novos fundamentos relacionados com a discussão acerca de futuras políticas públicas direcionadas a segmentos etários específicos, não só em relação às crianças e adolescentes, particularmente nos aspectos vinculados à saúde, educação e atenção materno-infantil, como também aos jovens, adultos e idosos, sobretudo no que concerne às políticas de emprego, previdência social e serviços de saúde, que assumem, cada vez mais, um grau crescente de complexidade.

As questões apresentadas, de certa forma, expõem evidências a respeito das causas que deveriam nortear a sociedade brasileira, em especial os gestores responsáveis pela formulação das políticas públicas, a adquirir consciência sobre o real significado das novas realidades demográficas e seus desdobramentos sobre a formulação de políticas públicas direcionadas a grupos sociais específicos. Essa tomada de consciência, caso tivesse se verificado no decorrer do processo de transição, poderia, por exemplo, ter norteado decisões, na área das políticas socioeconômicas, com desdobramentos positivos como maior oferta de emprego e melhorias na distribuição da renda. Além disso, há que se chamar a atenção para o fato de que se, na questão relacionada com os idosos, ainda existem dúvidas quanto ao encaminhamento de soluções relativas ao conjunto de medidas para a seguridade social e atenção a novas necessidades de saúde, devido a seu grau de complexidade, dúvidas de natureza similar também existem em relação às crianças e adolescentes.

Se se partir do princípio de que a população, independentemente de sua estrutura etária, deva usufruir os direitos de cidadania, é lícito considerar que os sistemas públicos envolvidos com a seguridade e a assistência sociais devam ser regidos por regras de contribuição, critérios de benefícios e transferências de fundos públicos que possam proteger e sustentar as condições materiais de vida desses contingentes populacionais, sobretudo os componentes de famílias mais carentes.

No caso específico do grupo dos idosos, a questão fundamental será garantir um sistema previdenciário que permita uma qualidade de vida e sobrevivência digna, num país, em que, ser idoso ainda é um risco, uma vez que a sociedade, de um modo geral, ainda não está organizada, pelo fato de ainda não ter tomado plena consciência do processo de mudança profunda que se vem processando no perfil demográfico brasileiro, em que a tendência é de aumento contínuo da participação deste grupo etário específico na estrutura populacional, 
conforme apresentado neste capítulo. Consequentemente, mudanças de cultura e educação direcionadas à valorização dos idosos são fundamentais, sendo, portanto, precondições para decisões em várias áreas importantes, como a de saúde - ampliação e melhoria no atendimento, preparação de quadros técnicos e profissionais especializados em geriatria, fisioterapia, terapia ocupacional etc. -, e de infraestrutura urbana, adequando o espaço urbano e moradias a esse grupo específico que, conforme observado, vem tendo, cada vez mais, um peso crescente na estrutura populacional brasileira, pressupondo, também, a necessidade de fortalecimento dos programas previdenciários.

No tocante à situação específica do grupo de crianças e adolescentes de 0 a 14 anos de idade, as tendências demográficas parecem assinalar em direções mais favoráveis, uma vez que se vem observando uma tendência de declínio, tanto em termos absolutos como relativos.

Conhecendo-se a nova realidade demográfica, passa-se a dispor de novos elementos suscetíveis de convergir para um melhor equacionamento de problemas crônicos que vêm afetando esses grupos etários, sobretudo os pertencentes a famílias mais carentes. Contudo, é importante alertar que a redução dos níveis de fecundidade não é garantia, por si só, da solução automática dos problemas sociais com os quais o País ainda se defronta. É imprescindível que haja objetividade na demarcação das populações que serão foco das políticas sociais, tendo-se bem claro sua dimensão, características e tendências evolutivas, elementos fundamentais para o dimensionamento e a seleção correta dos grupos de risco e/ou das populações-alvo.

Tendo em vista as questões especificadas, é conveniente chamar a atenção para uma importante variável, que é a educação, e que afeta, sobretudo, as crianças. Pesquisas têm mostrado a existência de grandes distorções entre a série frequentada versus idade, pondo em evidência as deficiências do sistema e, em última análise, sua capacidade de absorção, retenção e progressão da oferta de vagas aos alunos. Há que levar em consideração também as causas de natureza social, visto que muitas famílias, como fonte de ajuda para a sobrevivência familiar, são forçadas a utilizar seus filhos como força de trabalho infantojuvenil, ainda não inteiramente eliminada no País, apesar da legislação vigente, proibindo tal prática.

De qualquer forma, é imperativo reforçar e monitorar as estratégias em curso (programas do governo federal na área da educação, Bolsa Família etc.), para reter estas crianças na escola e criar as infraestruturas escolares em municípios do País, onde elas ainda são inexistentes, apesar das melhorias que vêm se observando nos níveis de alfabetização, no decorrer dos anos. Além disso, deve-se ficar atento para a melhoria da qualidade do ensino, elemento cada vez mais importante, numa economia globalizada e competitiva.

Para atingir tal objetivo, tornam-se cada vez mais necessários investimentos na qualificação do corpo docente e remuneração condizente. Tais questões não podem deixar de ser focadas e enfrentadas, num momento em que o número de crianças em idade escolar começa a diminuir significativamente, na maioria dos municípios brasileiros não afetados por movimentos migratórios maciços. No caso dos municípios onde as taxas de analfabetismo são ainda elevadas, deve-se ter presente que esses são provavelmente municípios que expulsam população para centros mais urbanos dotados, em geral, de serviços de natureza pública. 
Resumindo, desperdiçar esta situação, extremamente favorável do ponto de vista demográfico, para solucionar de vez problemas desse tipo, é jogar fora algumas das chances futuras desta nação realmente vir a solucionar seus imensos problemas de pobreza e exclusão social (O PROCESSO..., 1998).

Finalmente, importante registrar que, ao se pensar em planejamento de políticas públicas, não se pode deixar de considerar as especificidades próprias de cada região que, no caso do Brasil, apresentou trajetórias distintas de transição demográfica, as quais vêm se refletindo, portanto, nas novas demandas dos distintos grupos sociopopulacionais abordados.

Em decorrência das informações apresentadas, não deixa de ser evidente que o processo de transição demográfica que o País atravessa, afeta diversamente os distintos grupos etários, para os quais deverão ser oferecidas soluções específicas:

- Melhorias de programas de qualidade relacionados com a saúde e a educação, no caso de crianças e adolescentes, na medida em que o número de beneficiários está em processo de redução;

- Aumento na oferta de empregos, no caso de jovens e adultos; e

- Atenção médico-psicológica, adequação da infraestrutura urbana e domiciliar, e fortalecimento dos programas previdenciários, dentre outros, no caso dos idosos.

Quanto a este último segmento populacional, ressalte-se que o processo de envelhecimento é muito mais amplo que uma modificação de pesos de uma determinada população, pois altera a vida dos indivíduos, as estruturas familiares, a demanda por políticas públicas e a distribuição de recursos na sociedade. A questão que está sendo colocada está relacionada com o impacto da nova dinâmica demográfica recente na demanda por cuidados de longa duração para a população idosa, sejam estes formais ou informais. Isto, porque, menos trabalhadores significa menos produção de riqueza, menos gente para consumir e, o que é mais perturbador, menos contribuintes para manter o sistema de previdência social, sobrecarregado pelo volume crescente de aposentados.

Há de tomar consciência de que, como o Brasil começa a enfrentar os problemas que atualmente afetam os países europeus, ainda existe algum tempo para observar e analisar as possíveis soluções, porventura, encontradas, de forma a subsidiar a solução de problemas relacionados com os impactos do envelhecimento e o declínio futuro da população. Mas já se podem vislumbrar algumas saídas para essa problemática e adotadas por esses países, a exemplo da existência de uma boa estrutura de creches e de leis que facilitam o retorno da mulher ao trabalho após a licença-maternidade. Além disso, é fundamental destacar que as medidas que podem permitir a muitos países conviver com o envelhecimento populacional passam por mudanças culturais. Nesse aspecto, uma das soluções, apesar de fortes resistências de segmentos importantes da sociedade seria, gradualmente, ir aumentando a idade para a aposentadoria que, possivelmente, evitaria a falência dos sistemas previdenciários. Como a tendência é envelhecer com cada vez mais saúde e, portanto, com maior disposição para continuar trabalhando, é possível que, mantendo a contribuição do trabalhador por mais três a cinco anos, por si só, geraria impactos altamente positivos no alívio das contas da previdência social. 
Em síntese, conforme exposto, a tendência é que os idosos tenham um peso cada vez mais expressivo na estrutura populacional brasileira em decorrência das alterações na dinâmica demográfica. Contudo, a questão que se coloca é saber se a sociedade brasileira tem consciência das implicações dessa nova pressão populacional sobre a estrutura de serviços que terá de ser gerada, de forma a atender adequadamente a esse "novo" estrato populacional.

\section{Referências}

BRASIL. Decreto n. 1.948, de 6 de julho de 1996. Regulamenta a lei n. 8.842, de 4 de janeiro de 1994, que dispõe sobre a política nacional do idoso, e dá outras providênicas. Diário Oficial [da] República Federativa do Brasil, Brasília, DF, ano 134, n. 128, 4 jul. 1996. Seção 1, p. 12277-12279. Disponível em: <http://www.presidencia.gov.br/legislacao>. Acesso em: jan. 2016.

. Lei n. 8.842, de 4 de janeiro de 1994. Dispõe sobre a política do idoso, cria o conselho nacional do idoso e dá outras providências. Diário Oficial [da] República Federativa do Brasil, Brasília, DF, ano 132, n. 3, 5 jan. 1994. Seção 1, p. 77-79. Disponível em: <http:// www.presidencia.gov.br/legislacao>. Acesso em: jan. 2016.

BRASS, W. Métodos para estudiar la fecundidad y la mortalidad en poblaciones con datos limitados. Santiago de Chile: Centro Latinoamericano de Demografía - Celade, 1974. 240 p. (Serie E, n. 4).

CHAMADA nutricional: um estudo sobre a situação nutricional das crianças do semi-árido brasileiro. Brasília, DF: Ministério do Desenvolvimento e Combate à Fome, 2006. 114 p. (Cadernos de estudos: desenvolvimento social em debate, n. 4). Disponível em: <http:// acervodigital.mds.gov.br/xmlui/handle/123456789/191>. Acesso em: jun. 2015.

CENSO DEMOGRÁFICO 2000. Nupcialidade e fecundidade: resultados da amostra. Rio de Janeiro: IBGE, 2003. Disponível em: <http://www.ibge.gov.br/home/estatistica/populacao/ censo2000/nupcialidade_fecundidade/tabela_regioes.shtm>. Acesso em: jun. 2015.

FARIA, V. E.; POTTER, J. E. Television, telenovelas, and fertility change in northeast Brazil. Austin: University of Texas at Austin, Texas Population Research Center, 1995. 30 p. (Texas population research center paper, n. 94-95-12). Artigo posteriormente traduzido para o português, por Heloísa Buarque de Almeida.

GWATKIN, D. R. Indications of change in developing country mortality trends: the end of an era? Population and Development Review, New York: Population Council, v. 6, n. 4, p. 615644, Dec. 1980.

INTERNAÇÕES hospitalares. In: BRASIL. Ministério da Saúde. Sistema de Informações Hospitalares do SUS - SIHISUS: arquivos dissemináveis para tabulação. Brasília, DF: Ministério da Saúde, Departamento de Informática do Sistema Único de Saúde - SUS - Datasus, [2014]. Disponível em: <http://www2.datasus.gov.br/DATASUS/index. php?area=0901 $>$. Acesso em: mar. 2014. 
MORTALIDADE infantil e na infância e riscos de mortalidade associados ao comportamento reprodutivo. In: PESQUISA nacional sobre demografia e saúde 1996: Brasil. Rio de Janeiro: Sociedade Civil Bem-Estar Familiar no Brasil - Bemfam, 1997. cap. 7, p. 95-102. Disponível em: <http://www.measuredhs.com/pubs/pdf/FR77/FR77.pdf>. Acesso em: mar. 2015.

O PROCESSO demográfico brasileiro. In: A INFÂNCIA brasileira nos anos 90. Brasília, DF: Fundo das Nações Unidas para a Infância - Unicef, 1998. p. 13-27.

PROJEÇÃO da população do Brasil por sexo e idade para o período 2000-2060; Projeção da população das unidades da federação por sexo e idade 2000-2030. Rio de Janeiro: IBGE, 2013. Disponível em: <http://www.ibge.gov.br/home/estatistica/populacao/projecao_da_ populacao/2013/default.shtm>. Acesso em: jun. 2015.

SANTOS, J. L. F. Demografia: estimativas e projeções: medidas de fecundidade e mortalidade para o Brasil no século XX. São Paulo: Universidade de São Paulo - USP, Faculdade de Arquitetura e Urbanismo: Fundação para Pesquisa Ambiental, 1978. 71 p. (Cadernos de estudo e pesquisa do Prodeur).

SIMÕES, C. C. da S. A mortalidade infantil na transição da mortalidade no Brasil: um estudo comparativo entre o nordeste e o sudeste. 1997. 178 p. Tese (Doutorado)-Centro de Desenvolvimento e Planejamento Regional, Universidade Federal de Minas Gerais, Belo Horizonte, 1997.

Perfis de saúde e de mortalidade no Brasil: uma análise de seus condicionantes em grupos populacionais específicos. Brasília, DF: Organização Pan-Americana da Saúde - OPAS, 2002. 141 p. Disponível em: <http://gestaocompartilhada.pbh.gov.br/sites/ gestaocompartilhada.pbh.gov.br/files/biblioteca/arquivos/mortalidade_no_brasil.pdf $>$. Acesso em: jun. 2015.

Relações entre as alterações históricas na dinâmica demográfica brasileira, políticas públicas e impactos futuros decorrentes do processo de envelhecimento da população. Rio de Janeiro: IBGE, Departamento de Pesquisas, 2016. No prelo.

A transição da fecundidade no Brasil: análise de seus determinantes e as novas questões demográficas. Brasília, DF: Fundo de População das Nações Unidas Brasil UNFPA; São Paulo: Arbeit Factory, 2006. 140 p. Disponível em: <http://www.unfpa.org.br/ Arquivos/transicao.pdf>. Acesso em: jun. 2015.

VETTER, D. M.; SIMÕES, C. C. da S. Acesso à infra-estrutura de saneamento básico e mortalidade. Revista Brasileira de Estatística, Rio de Janeiro: IBGE, v. 42, n. 165. p. 17-35, jan./mar. 1981. Disponível em: <http://biblioteca.ibge.gov.br/pt/biblioteca-catalogo?view=d etalhes\&id=7111>. Acesso em: jun. 2015. 
